\title{
Photolysis controls the isotopic composition of water products escaping Mars' atmosphere
}

Juan Alday ( $\nabla$ juan.aldayparejo@physics.ox.ac.uk)

University of Oxford https://orcid.org/0000-0003-1459-3444

Alexander Trokhimovskiy

Space Research Institute

Patrick Irwin

University of Oxford https://orcid.org/0000-0002-6772-384X

Colin Wilson

University of Oxford

Franck Montmessin

CNRS https://orcid.org/0000-0002-4187-1457

Franck Lefèvre

LATMOS https://orcid.org/0000-0001-5294-5426

Anna Fedorova

Space Research Institute

Denys Belyaev

Space Research Institute (IKI)

Kevin Olsen

University of Oxford https://orcid.org/0000-0002-2173-9889

Oleg Korablev

Space Research Institute (IKI) https://orcid.org/0000-0003-1115-0656

Margaux Vals

LATMOS

Loïc Rossi

LATMOS

\section{Lucio Baggio}

LATMOS https://orcid.org/0000-0002-9263-4937

Jean-Loup Bertaux

LATMOS / CNRS

Andrey Patrakeev

Space Research Institute

Alexey Shakun

Space Research Institute (IKI) 


\section{Article}

Keywords: photolysis, Mars, atmosphere

Posted Date: January 12th, 2021

DOl: https://doi.org/10.21203/rs.3.rs-128379/v1

License: (c) (i) This work is licensed under a Creative Commons Attribution 4.0 International License. Read Full License

Version of Record: A version of this preprint was published at Nature Astronomy on June 24th, 2021. See the published version at https://doi.org/10.1038/s41550-021-01389-x. 


\section{Photolysis controls the isotopic composition of water products escaping}

\section{Mars' atmosphere}

3 Juan Alday $^{\mathrm{a} *}$, A. Trokhimovskiy ${ }^{\mathrm{b}}$, P. G. J. Irwin ${ }^{\mathrm{a}}$, C. F. Wilson ${ }^{\mathrm{a}}$, F. Montmessin ${ }^{\mathrm{c}}$, F. Lefèvre ${ }^{\mathrm{c}}$,

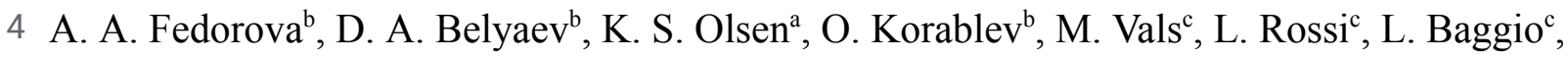

5 J. L. Bertaux ${ }^{c}$, A. Patrakeev ${ }^{\mathrm{b}}$ and A. Shakun .

6 a AOPP, Department of Physics, University of Oxford, Oxford, United Kingdom;

$7{ }^{b}$ Space Research Institute (IKI), Moscow, Russia

$8{ }^{c}$ LATMOS/CNRS, Guyancourt, France.

9

11 * Corresponding author. E-mail: juan.aldayparejo@physics.ox.ac.uk 


\section{Abstract}

31 The current Martian atmosphere is about five times more enriched in deuterium than Earth's,

32 providing a direct testimony that Mars hosted several times more water in its early youth than

33 nowadays. Estimates of the total amount of water lost to space from the current mean $\mathrm{D} / \mathrm{H}$

34 value depend on a rigorous appraisal of the relative escape between deuterated and

35 non-deuterated water. The transport of water to the upper atmosphere, from whence it may

36 escape to space, has been assumed to be controlled by water condensation and photolysis,

37 both of which affect the isotope composition of the escaping hydrogen. Their respective role

38 in influencing the relative proportion of escaping $\mathrm{D}$ and $\mathrm{H}$ atom populations in the upper

39 atmosphere has remained speculative. Here we report $\mathrm{HDO}$ and $\mathrm{H}_{2} \mathrm{O}$ profiles observed by the

40 Atmospheric Chemistry Suite (ExoMars Trace Gas Orbiter) in orbit around Mars that, once

41 combined with expected photolysis rates, reveal that the ultraviolet dissociation of water not

42 only governs the production of atomic hydrogen, prevailing over the ion chemistry

43 mechanism, but also dominates the production of $\mathrm{H}$ relative to $\mathrm{D}$ atoms, disrupting the old

44 paradigm of atmospheric condensation being the main process differentiating $\mathrm{D}$ and $\mathrm{H}$ in the

45 upper atmosphere.

\section{Main text}

47 The isotope composition of the Martian atmosphere has often been used as a means to

48 understand its evolution ${ }^{1}$. Assuming that Earth and Mars were assembled out of the same

49 material, the relative enrichment of heavy isotopes in Martian atmospheric water vapour with

50 respect to Earth suggests that the escape of water throughout the Martian history has been

51 substantial ${ }^{2-11}$, consistent with the geomorphological and mineralogical imprints on the 
52 surface, which require the presence of liquid water on ancient Mars ${ }^{12,13}$. Although these clues

53 indicate that water was abundant in the past, the amount that existed remains uncertain.

54 Estimations of the size of the ancient water reservoir on Mars from its isotope composition

55 depend not only on the present-day atmospheric ratio, but also on the net escape fractionation

56 factor, $f$. This factor relates the efficiency of escape of $\mathrm{D}$ with respect to $\mathrm{H}$, including all

57 fractionation processes occurring along the physical and chemical pathways by which the

58 initial $\mathrm{H}_{2} \mathrm{O}$ and $\mathrm{HDO}$ molecules are decomposed and ultimately escape to space by either

59 thermal or non-thermal means ${ }^{14-17}$.

60 The initial part of the process by which water escapes to space comprises the production of

61 atomic $\mathrm{H}$ and $\mathrm{D}$ from water vapour. For a long time, this production was assumed to be

62 sourced by long-lived molecular hydrogen, which is formed as a by-product of the catalytic

63 recombination of carbon dioxide with odd-hydrogen $\left(\mathrm{H}, \mathrm{OH}, \mathrm{HO}_{2}\right)$ produced in the

64 dissociation of $\mathrm{H}_{2} \mathrm{O}^{15}$. However, observations of atomic hydrogen in the upper atmosphere

65 reveal variations not consistent with the sole production by molecular hydrogen ${ }^{18}$, which

66 might be produced by the direct photodissociation of water vapour in the middle

67 atmosphere ${ }^{19,20}$. In both of these scenarios, two factors can fractionate the production of

68 deuterium relative to hydrogen: 1) the preferential photolysis of $\mathrm{H}_{2} \mathrm{O}$ molecules relative to

69 HDO depletes the dissociation products in deuterium ${ }^{21}$; 2) the preferential condensation of

70 HDO in water ice clouds ${ }^{23}$ leaves the atmosphere depleted in the heavy isotopes above the

71 condensation level, which can impact the supply of $\mathrm{D} / \mathrm{H}$ to the upper atmosphere, if

72 photolysis occurs above the cloud deck ${ }^{24,25}$. Both of these mechanisms are expected to

73 fractionate the isotopic composition of atomic hydrogen, although the effectiveness of each

74 of these remains unknown. 
75 We investigate the vertical distribution of the isotope composition $\left(\mathrm{D} / \mathrm{H}\right.$ and $\left.{ }^{18} \mathrm{O} /{ }^{16} \mathrm{O}\right)$ of water

76 vapour in the Martian atmosphere using solar occultation measurements made by the

77 mid-infrared (MIR) channel of the Atmospheric Chemistry Suite (ACS) ${ }^{26}$ onboard the

78 ExoMars Trace Gas Orbiter (TGO). ACS MIR is an echelle cross dispersion spectrometer

79 dedicated to solar occultation measurements in a spectral range between 2.2 and $4.4 \mu \mathrm{m}$. Its

80 novel design allows the simultaneous selection of 9 to 25 contiguous diffraction orders within

81 the entire spectral range of the instrument, achieving high resolving power $(\lambda / \Delta \lambda \sim 30,000)$ in

82 a wide instantaneous spectral range $(0.15-0.3 \mu \mathrm{m})$. The dataset assembled for this study

83 includes all available ACS MIR solar occultation observations made using secondary grating

84 position 4, which allows the selection of ten diffraction orders (215-224) in a spectral range

85 between 2.65-2.77 $\mu \mathrm{m}\left(3600-3770 \mathrm{~cm}^{-1}\right)$, encompassing absorption bands of several

86 isotopologues of carbon dioxide and water vapour (see Supplementary Methods). To date,

87 there are 549 secondary grating position 4 solar occultations, which account for

88 approximately $14 \%$ of all available ACS MIR observations, covering more than a full

89 Martian year of observations and including more than half of Martian Year $34(\mathrm{MY} 34)\left(\mathrm{L}_{\mathrm{s}}=\right.$

$\left.90160-360^{\circ}\right)$ and of $\mathrm{MY} 35\left(\mathrm{Ls}=0-290^{\circ}\right)$. The observational coverage used in this dataset

91 allows the analysis of the variations of the $\mathrm{D} / \mathrm{H}$ ratio in three dimensions, including the

92 vertical, latitudinal, and seasonal effects.

93 The analysis of the data and the retrieval of the atmospheric vertical profiles is performed

94 using the NEMESIS (Nonlinear optimal Estimator for MultivariatE spectral analySIS)

95 algorithm ${ }^{27}$, which utilises the optimal estimation framework ${ }^{28}$. In particular, the retrieval

96 scheme is performed in two steps. First, vertical profiles of pressure and temperature are

97 retrieved from $\mathrm{CO}_{2}$ absorption, along with the vertical distribution of the $\mathrm{H}_{2}{ }^{16} \mathrm{O}$ volume 
98 mixing ratio. Secondly, the pressure and temperature profiles are fixed, and the retrieved

$99 \mathrm{H}_{2}{ }^{16} \mathrm{O}$ volume mixing ratio is used as an a priori estimate to retrieve the volume mixing ratios

100 of $\mathrm{H}_{2}{ }^{16} \mathrm{O}, \mathrm{H}_{2}{ }^{18} \mathrm{O}$ and $\mathrm{HD}^{16} \mathrm{O}$, assuming an a priori isotopic composition of ${ }^{18} \mathrm{O} /{ }^{16} \mathrm{O}=1$ and

$101 \mathrm{D} / \mathrm{H}=5$ with respect to the Vienna Standard Mean Ocean Water (VSMOW; D/H $=1.6 \times 10^{-4}$

102 and ${ }^{18} \mathrm{O} /{ }^{16} \mathrm{O}=2.0 \times 10^{-3}$ ), and using a spectral window suitable for the derivation of the

103 isotopic ratios (see Fig. 1). More details describing the retrieval scheme and its validation are

104 given in the Supplementary Methods.

106 Figure 2 shows a summary of the climatology of the retrieved parameters from the spectra.

107 During the observed period, both temperature and $\mathrm{H}_{2} \mathrm{O}$ volume mixing ratio profiles show

108 drastic seasonal and latitudinal changes. During the Southern Hemisphere (SH) spring and

109 summer seasons $\left(\mathrm{L}_{\mathrm{s}}=180^{\circ}\right.$ and $\left.\mathrm{L}_{\mathrm{s}}=270^{\circ}\right)$ in both MY34 and MY35, Mars is close to

110 perihelion $\left(\mathrm{L}_{\mathrm{s}}=251^{\circ}\right)$, and the greater dust heating and proximity to the Sun intensify the

111 Hadley circulation ${ }^{29}$, allowing warmer temperatures to expand to the middle atmosphere in

112 both the northern and southern hemispheres. These greater temperatures move the

113 hygropause (i.e. level at which water vapour saturates) upwards to higher altitudes, allowing

114 water vapour to migrate to the middle and upper atmospheres, and reaching values greater

115 than $50 \mathrm{ppmv}$ as high as $100 \mathrm{~km}$. On the other hand, during the Northern Hemisphere (NH)

116 spring and summer seasons $\left(\mathrm{L}_{\mathrm{s}}=0^{\circ}\right.$ and $\left.\mathrm{L}_{\mathrm{s}}=90^{\circ}\right)$, although high water vapour abundances $(>$

$117150 \mathrm{ppmv}$ ) are observed in the $\mathrm{NH}$, these are confined to altitudes below $\sim 20 \mathrm{~km}$. At high

118 southern latitudes $\left(>60^{\circ} \mathrm{S}\right)$, during this time, very low water vapour abundances $(<1 \mathrm{ppmv})$

119 and temperatures $(<150 \mathrm{~K})$ are observed. These seasonal trends are in agreement with other 
120 observations ${ }^{30-33}$ and with the expectations from the simulations of a General Circulation

121 Model $(\mathrm{GCM})^{34}$.

122 The measurements also depict a very dynamic behaviour of the $\mathrm{D} / \mathrm{H}$ ratio, varying from 1 to

1236 VSMOW, with an isotopic ratio representative of the present-day Martian atmosphere of 5

$124 \pm 0.4$ VSMOW (see Supplementary Methods). During the SH summer, $\mathrm{H}_{2} \mathrm{O}$ and HDO in both

125 hemispheres expand into the middle atmosphere, exhibiting isotopic ratios between 4-6

126 VSMOW up to $40-60 \mathrm{~km}$, until they reach the saturation level. Above this level, the D/H

127 ratio starts to decrease down to values between 1-3 VSMOW, as predicted by the preferential

128 condensation of $\mathrm{HDO}$ over $\mathrm{H}_{2} \mathrm{O}$ during the formation of water ice clouds ${ }^{22,25}$. The presence of

129 isotopic fractionation in condensation processes is even clearer during the NH summer, which

130 shows a steady decrease of the $\mathrm{D} / \mathrm{H}$ ratio from 4-5 VSMOW at $10 \mathrm{~km}$ down to 2-3 VSMOW

131 at 20-30 km, due to a lower altitude of the hygropause (see Figs. 2 and S8).

132

133 The variations in the $\mathrm{D} / \mathrm{H}$ ratio are found to be positively correlated with those in the water

134 vapour volume mixing ratio (see Fig. S9). A logarithmic relation between $\mathrm{D} / \mathrm{H}$ and water

135 vapour abundance is predicted by the isotope fractionation during condensation ${ }^{25}$, which

136 appears therefore responsible for the observed variations. Similarly, the observed variations

137 of the $\mathrm{D} / \mathrm{H}$ ratio appear to be related to the atmospheric temperature: while the higher values

138 of the $\mathrm{D} / \mathrm{H}$ ratio ( $>4 \mathrm{VSMOW})$ are found in a wide range of temperatures $(170-210 \mathrm{~K})$, low

139 values of $\mathrm{D} / \mathrm{H}(<3 \mathrm{VSMOW})$ are only measured for $\mathrm{T}<180 \mathrm{~K}$. This correlation corroborates

140 the hypothesis of the prominent role of condensation-induced fractionation, which is

141 predicted to increase with decreasing temperatures ${ }^{4,5,22,35}$. 
143 The ${ }^{18} \mathrm{O} /{ }^{16} \mathrm{O}$ is found to be much less variable than the $\mathrm{D} / \mathrm{H}$ ratio. The value representative of

144 the present-day atmospheric ratio is found to be $1.14 \pm 0.08 \mathrm{VSMOW}$, which is in line with

145 values reported in previous studies ${ }^{3,11}$. We observe variations ranging between 0.9 and 1.3

146 VSMOW, although this level of variability is in the same range as the typical measurement

147 uncertainty, which makes it difficult to disentangle potential variations of the isotopic ratios

148 from statistical noise (see Supplementary Methods). Expectations from isotopic fractionation

149 in condensation processes predict a preferential condensation of $\mathrm{H}_{2}{ }^{18} \mathrm{O}$ over $\mathrm{H}_{2}{ }^{16} \mathrm{O}$, similar

150 than for the $\mathrm{D} / \mathrm{H}$ ratio, but with a lower magnitude ${ }^{22,23,36}$. The absence of measured variability

151 does not rule out the presence of fractionation processes though, since they might be smaller

152 than, and therefore masked by the measurement uncertainty (see Fig. S9).

153

154 Estimations of how $\mathrm{H}_{2} \mathrm{O}$ and $\mathrm{HDO}$ molecules are fractionated as they are photodissociated

155 into lighter molecules $(\mathrm{OH}+\mathrm{H})$ are made with the photolysis code of the LMD-GCM ${ }^{21,37}$ (see

156 Supplementary Methods). These calculations are combined with ACS MIR water vapour

157 density vertical profiles to estimate the dissociation rates, which reveal the perihelion season

158 to be dominant in the dissociation of water vapour, with rates approximately 100 times

159 greater than those found close to aphelion (see Fig. 3A). This result is consistent with

160 measurements of the $\mathrm{H}$ and D Lyman- $\alpha$ brightness, representative of atomic $\mathrm{H}$ and $\mathrm{D}$

161 atmospheric densities, which show peak values around perihelion ${ }^{38-40}$. Our calculations

162 indicate column-integrated photodissociation rates of at least $10^{11} \mathrm{~cm}^{-2} \mathrm{~s}^{-1}$ during the

163 perihelion season, which are between one and two orders of magnitude higher than those

164 predicted by the formation of atomic hydrogen from ion chemistry ${ }^{41}$, evidencing the prevalent

165 role of photolysis in the production of atomic hydrogen. 
167 We calculated the fractionation factor relating the $\mathrm{D} / \mathrm{H}$ ratio in the photolysis products with

168 respect to the mean $\mathrm{D} / \mathrm{H}$ ratio representative of water in the lower atmosphere $(\mathrm{F}=$

$\left.169(\mathrm{D} / \mathrm{H})_{\text {bulk }} /(\mathrm{D} / \mathrm{H})_{\text {products }}\right)$, taking into account the impact of both photolysis-induced fractionation

$170 F_{p}$ (i.e., fractionation due to the difference in the photolysis cross sections of $\mathrm{HDO}$ and $\mathrm{H}_{2} \mathrm{O}$ )

171 and condensation-induced fractionation $F_{c}$ (i.e., fractionation due to the depletion in $\mathrm{D} / \mathrm{H}$ of

172 the parent water molecules with respect to the average $\mathrm{D} / \mathrm{H}$ ratio of water in the lower

173 atmosphere). More details about how these calculations are performed are given in the

174 Supplementary Methods. Our calculations suggest that, while the dissociation products are

175 expected to have a $\mathrm{D} / \mathrm{H}$ ratio about 2-2.5 times lower than the average $\mathrm{D} / \mathrm{H}$ ratio in the lower

176 atmosphere $\left(\mathrm{D} / \mathrm{H}_{\text {bulk }}=5 \pm 0.4\right.$ VSMOW) during perihelion, the fractionation factor $F$ would

177 increase up to 5-6 during aphelion (see Fig. 3B). However, the dissociation rates during the

178 aphelion season are between one and two orders of magnitude lower than during perihelion

179 and are therefore expected to have a minor contribution to the annual average (see Fig. 3B).

180 Consequently, the annual average $\mathrm{D} / \mathrm{H}$ fractionation factor $F$ is heavily weighted towards

181 perihelion, which is in agreement with the measurement of the $\mathrm{D} / \mathrm{H}$ ratio in molecular

182 hydrogen, which was found to be approximately 2.5 times smaller than the $\mathrm{D} / \mathrm{H}$ ratio in

183 water $^{15}$.

185 While condensation-induced fractionation appears to be the main driver of the variations of

186 the $\mathrm{D} / \mathrm{H}$ ratio in atmospheric water vapour, it has a minor influence on shaping the isotopic

187 composition of the dissociation products as compared to photolysis-induced fractionation.

188 During perihelion, at the altitudes at which photolysis is more efficient $(40-50 \mathrm{~km})$, while 
189 water vapour is still not affected by condensation $\left(F_{\text {cond }} \sim 1\right)$, the photolysis-induced

190 fractionation factor is expected to be about $F_{\text {photo }} \sim 2.0-2.5$ (see Fig. S11). During aphelion,

191 the role of condensation-induced fractionation increases with respect to perihelion $\left(F_{\text {cond }} \sim\right.$

192 1.5-2.0), but so does the role of photolysis-induced fractionation $\left(F_{\text {photo }} \sim 1.5-2.0\right)$ (see Fig.

193 S12). Besides, as previously mentioned, the role of the aphelion season in the dissociation of

194 water vapour is expected to be negligible with respect to perihelion. Our results provide new

195 insights for resolving the old paradigm regarding the role of the different mechanisms to

196 fractionate the $\mathrm{D} / \mathrm{H}$ ratio of water vapour in the lower atmosphere and that of its dissociation

197 products, leading to the enrichment of $\mathrm{D} / \mathrm{H}$ in the atmosphere as it escapes into space $\mathrm{e}^{21,24,42}$.

199 Similarly, as for HDO, the $\mathrm{H}_{2}{ }^{18} \mathrm{O}$ molecules are expected to have a different UV absorption

200 cross-section than the $\mathrm{H}_{2}{ }^{16} \mathrm{O}$ ones, which can impact the isotope composition of the

201 dissociation products of water vapour and the efficiency of ${ }^{18} \mathrm{O}$ to reach the upper

202 atmosphere ${ }^{43}$. We estimate that, while the dissociation products are expected to be about 2-2.5

203 times depleted in $\mathrm{D} / \mathrm{H}$ with respect to the ratio in water vapour in the lower atmosphere, this

204 factor would just be $1.08-1.10$ for the ${ }^{18} \mathrm{O} /{ }^{16} \mathrm{O}$ ratio, revealing a much higher efficiency of ${ }^{18} \mathrm{O}$

205 to be transferred to the dissociation products with respect to D (see Supplementary Methods).

206 This might explain the dichotomy between the large enrichment in the heavy isotope of the

$207 \mathrm{D} / \mathrm{H}$ ratio ( $~ 5$ VSMOW) as opposed to the mild enrichment in the ${ }^{18} \mathrm{O} /{ }^{16} \mathrm{O}$ ratio $(\sim 1.14$

208 VSMOW): while ${ }^{18} \mathrm{O}$ is efficiently transferred to the photolysis products of water vapour,

209 HDO molecules are less efficiently photolyzed, decreasing the $\mathrm{D} / \mathrm{H}$ ratio of the lighter species

210 that ultimately the escape to space. Therefore, as $\mathrm{H}$ and $\mathrm{O}$ escape from the Martian

211 atmosphere, they will enrich more efficiently the $\mathrm{D} / \mathrm{H}$ ratio than the ${ }^{18} \mathrm{O} /{ }^{16} \mathrm{O}$ ratio. 
212 Nevertheless, it must also be noted that, while the $\mathrm{O}$ isotopic composition of the atmosphere

213 may be buffered by interactions with the $\mathrm{O}$ in the surface, atmospheric-surface interactions

214 are expected to have a lower influence on the $\mathrm{H}$ isotopic composition of the atmosphere ${ }^{1,16,44}$.

\section{References}

216 1. Jakosky, B. M. Mars volatile evolution: Evidence from stable isotopes. Icarus 94, 14-31 217 (1991).

218 2. Owen, T., Maillard, J. P., de Bergh, C. \& Lutz, B. L. Deuterium on Mars: The Abundance 219 of HDO and the Value of D/H. Science 240, 1767-1767 (1988).

220 3. Webster, C. R. et al. Isotope Ratios of $\mathrm{H}, \mathrm{C}$, and $\mathrm{O}$ in $\mathrm{CO} 2$ and $\mathrm{H} 2 \mathrm{O}$ of the Martian 221 Atmosphere. Science 341, 260-263 (2013).

222 4. Villanueva, G. L. et al. Strong water isotopic anomalies in the martian atmosphere: Probing current and ancient reservoirs. Science 348, 218-221 (2015).

5. Krasnopolsky, V. A. Variations of the $\mathrm{HDO} / \mathrm{H} 2 \mathrm{O}$ ratio in the martian atmosphere and loss of water from Mars. Icarus 257, 377-386 (2015).

6. Aoki, S. et al. Seasonal variation of the $\mathrm{HDO} / \mathrm{H} 2 \mathrm{O}$ ratio in the atmosphere of Mars at the middle of northern spring and beginning of northern summer. Icarus 260, 7-22 (2015).

229 7. Encrenaz, T. et al. A map of $\mathrm{D} / \mathrm{H}$ on Mars in the thermal infrared using EXES aboard SOFIA. Astron. Astrophys. 586, A62 (2016).

231 8. Encrenaz, T. et al. New measurements of D/H on Mars using EXES aboard SOFIA. 232 Astron. Astrophys. 612, A112 (2018).

233 9. Khayat, A. S. J., Villanueva, G. L., Smith, M. D. \& Guzewich, S. D. IRTF/CSHELL 234 mapping of atmospheric $\mathrm{HDO}, \mathrm{H} 2 \mathrm{O}$ and $\mathrm{D} / \mathrm{H}$ on Mars during northern summer. Icarus 330, 204-216 (2019).

236 10. Vandaele, A. C. et al. Martian dust storm impact on atmospheric $\mathrm{H} 2 \mathrm{O}$ and $\mathrm{D} / \mathrm{H}$ observed 237 by ExoMars Trace Gas Orbiter. Nature 568, 521-525 (2019). 
11. Alday, J. et al. Oxygen isotopic ratios in Martian water vapour observed by ACS MIR on board the ExoMars Trace Gas Orbiter. Astron. Astrophys. 630, A91 (2019).

12. Carr, M. H. \& Clow, G. D. Martian channels and valleys: Their characteristics, distribution, and age. Icarus 48, 91-117 (1981).

13. Baker, V. R. Water and the martian landscape. Nature 412, 228-236 (2001).

14. Krasnopolsky, V. On the Deuterium Abundance on Mars and Some Related Problems. Icarus 148, 597-602 (2000).

15. Krasnopolsky, V. A. Mars' upper atmosphere and ionosphere at low, medium, and high solar activities: Implications for evolution of water. J. Geophys. Res. Planets 107, $11-1-11-11(2002)$.

16. Fox, J. L. \& Hać, A. Isotope fractionation in the photochemical escape of $O$ from Mars. Icarus 208, 176-191 (2010).

17. Cangi, E. M., Chaffn, M. S. \& Deighan, J. Higher Martian atmospheric temperatures at all altitudes increase the D/H fractionation factor and water loss. J. Geophys. Res. Planets (2020) doi:10.1029/2020JE006626.

18. Chaffin, M. S. et al. Unexpected variability of Martian hydrogen escape. Geophys. Res. Lett. 41, 314-320 (2014).

19. Chaffin, M. S., Deighan, J., Schneider, N. M. \& Stewart, A. I. F. Elevated atmospheric escape of atomic hydrogen from Mars induced by high-altitude water. Nat. Geosci. 10, 174-178 (2017).

20. Heavens, N. G. et al. Hydrogen escape from Mars enhanced by deep convection in dust storms. Nat. Astron. 2, 126-132 (2018).

21. Cheng, B.-M. et al. Photo-induced fractionation of water isotopomers in the Martian atmosphere. Geophys. Res. Lett. 26, 3657-3660 (1999).

22. Merlivat, L. \& Nief, G. Fractionnement isotopique lors des changements d'état solide-vapeur et liquide-vapeur de l'eau à des températures inférieures à $0^{\circ} \mathrm{C}$. Tellus 19 , 122-127 (1967).

23. Majoube, M. Fractionation Factor of 180 between Water Vapour and Ice. Nature 226, 
1242-1242 (1970).

267 24. Bertaux, J.-L. \& Montmessin, F. Isotopic fractionation through water vapor condensation:

268 The Deuteropause, a cold trap for deuterium in the atmosphere of Mars. J. Geophys.

269 Res. Planets 106, 32879-32884 (2001).

270 25. Montmessin, F., Fouchet, T. \& Forget, F. Modeling the annual cycle of HDO in the

271 Martian atmosphere: A 3-D STUDY OF MARTIAN HDO. J. Geophys. Res. Planets 110,

272 n/a-n/a (2005).

273 26. Korablev, O. et al. The Atmospheric Chemistry Suite (ACS) of Three Spectrometers for 274 the ExoMars 2016 Trace Gas Orbiter. Space Sci. Rev. 214, 7 (2018).

275 27. Irwin, P. G. J. et al. The NEMESIS planetary atmosphere radiative transfer and retrieval

276 tool. J. Quant. Spectrosc. Radiat. Transf. 109, 1136-1150 (2008).

277 28. Rodgers, C. D. Inverse Methods for Atmospheric Sounding: Theory and Practice. vol. 2 278 (WORLD SCIENTIFIC, 2000).

279 29. Olsen, K. S. et al. The vertical structure of $\mathrm{CO}$ in the Martian atmosphere as observed by 280 ACS on ExoMars TGO. Accept. Nat. Geosci. (2020).

281 30. Trokhimovskiy, A. et al. Mars' water vapor mapping by the SPICAM IR spectrometer:

282 Five martian years of observations. Icarus 251, 50-64 (2015).

283 31. Fedorova, A. A. et al. Stormy water on Mars: The distribution and saturation of 284 atmospheric water during the dusty season. Science 367, 297-300 (2020).

285 32. Fedorova, A. et al. Multi-annual monitoring of the water vapor vertical distribution on 286 Mars by SPICAM on Mars Express. J. Geophys. Res. Planets (2020) doi:10.1029/2020JE006616.

288 33. Aoki, S. et al. Water Vapor Vertical Profiles on Mars in Dust Storms Observed by

289 TGO/NOMAD. J. Geophys. Res. Planets 124, 3482-3497 (2019).

290 34. Montmessin, F., Forget, F., Rannou, P., Cabane, M. \& Haberle, R. M. Origin and role of 291 water ice clouds in the Martian water cycle as inferred from a general circulation model.

292 J. Geophys. Res. Planets 109, (2004).

293 35. Lamb, K. D. et al. Laboratory measurements of $\mathrm{HDO} / \mathrm{H}_{2} \mathrm{O}$ isotopic fractionation during 
ice deposition in simulated cirrus clouds. Proc. Natl. Acad. Sci. 114, 5612-5617 (2017).

36. Casado, M. et al. Experimental determination and theoretical framework of kinetic fractionation at the water vapour-ice interface at low temperature. Geochim. Cosmochim. Acta 174, 54-69 (2016).

37. Lefèvre, F., Lebonnois, S., Montmessin, F. \& Forget, F. Three-dimensional modeling of ozone on Mars. J. Geophys. Res. Planets 109, (2004).

38. Bhattacharyya, D., Clarke, J. T., Bertaux, J.-L., Chaufray, J.-Y. \& Mayyasi, M. A strong seasonal dependence in the Martian hydrogen exosphere: SEASONAL DEPENDENCE OF MARTIAN H ESCAPE. Geophys. Res. Lett. 42, 8678-8685 (2015).

39. Halekas, J. S. Seasonal variability of the hydrogen exosphere of Mars: Mars Hydrogen. J. Geophys. Res. Planets 122, 901-911 (2017).

40. Clarke, J. T. et al. Variability of $\mathrm{D}$ and $\mathrm{H}$ in the Martian upper atmosphere observed with the MAVEN IUVS echelle channel. J. Geophys. Res. Space Phys. 122, 2336-2344 (2017).

41. Stone, S. W. et al. Hydrogen escape from Mars is driven by seasonal and dust storm transport of water. Science 370, 824-831 (2020).

42. Krasnopolsky, V. A., Mumma, M. J. \& Gladstone, G. R. Detection of Atomic Deuterium in the Upper Atmosphere of Mars. Science 280, 1576-1580 (1998).

43. Miller, C. E. \& Yung, Y. L. Photo-induced isotopic fractionation. J. Geophys. Res. Atmospheres 105, 29039-29051 (2000).

44. Jakosky, B. M., Pepin, R. O., Johnson, R. E. \& Fox, J. L. Mars Atmospheric Loss and Isotopic Fractionation by Solar-Wind-Induced Sputtering and Photochemical Escape. Icarus 111, 271-288 (1994).

45. Trokhimovskiy, A. et al. First observation of the magnetic dipole $\mathrm{CO}_{2}$ absorption band at 3.3 textmu $\mathrm{m}$ in the atmosphere of Mars by the ExoMars Trace Gas Orbiter ACS instrument. Astron. Astrophys. 639, A142 (2020).

46. Hase, F., Wallace, L., McLeod, S. D., Harrison, J. J. \& Bernath, P. F. The ACE-FTS atlas of the infrared solar spectrum. J. Quant. Spectrosc. Radiat. Transf. 111, 521-528 (2010). 
322 47. Gordon, I. E. et al. The HITRAN2016 molecular spectroscopic database. J. Quant. 323 Spectrosc. Radiat. Transf. 203, 3-69 (2017).

324 48. Régalia, L. et al. Laboratory measurements and calculations of line shape parameters of 325 the H2O-CO2 collision system. J. Quant. Spectrosc. Radiat. Transf. 231, 126-135 326 (2019).

327 49. Devi, V. M. et al. Line parameters for CO2- and self-broadening in the $\mathrm{v} 1$ band of 328 HD16O. J. Quant. Spectrosc. Radiat. Transf. 203, 133-157 (2017).

329 50. Devi, V. M. et al. Line parameters for CO2 broadening in the v2 band of HD16O. J. 330 Quant. Spectrosc. Radiat. Transf. 187, 472-488 (2017).

331 51. Devi, V. M. et al. Line parameters for CO2- and self-broadening in the $\mathrm{v} 3$ band of 332 HD16O. J. Quant. Spectrosc. Radiat. Transf. 203, 158-174 (2017).

333 52. Forget, F. et al. Improved general circulation models of the Martian atmosphere from the 334 surface to above 80 km. J. Geophys. Res. Planets 104, 24155-24175 (1999).

335 53. Quémerais, E. et al. Stellar occultations observed by SPICAM on Mars Express. J. 336 Geophys. Res. 111, E09S04 (2006).

337 54. Montmessin, F. et al. Stellar occultations at UV wavelengths by the SPICAM instrument: 338 Retrieval and analysis of Martian haze profiles. J. Geophys. Res. 111, E09S09 (2006).

339 55. Irwin, P. G. J. et al. Probable detection of hydrogen sulphide (H2S) in Neptune's 340 atmosphere. Icarus 321, 550-563 (2019).

341 56. Alsaeed, N. R. \& Jakosky, B. M. Mars Water and D/H Evolution From 3.3 Ga to Present. 342 J. Geophys. Res. Planets 124, 3344-3353 (2019).

343 57. Lefèvre, F. Three-dimensional modeling of ozone on Mars. J. Geophys. Res. 109, $344 \quad$ E07004 (2004). 


\section{Figures}
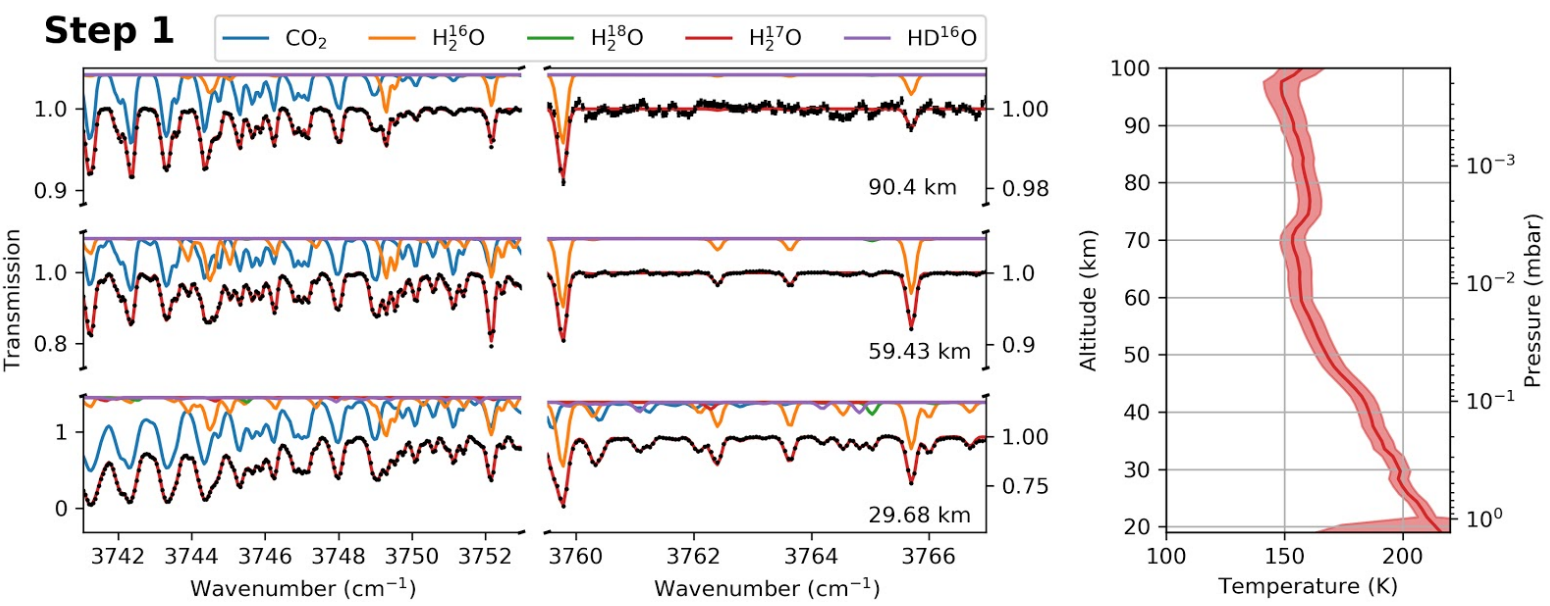

\section{Step 2}
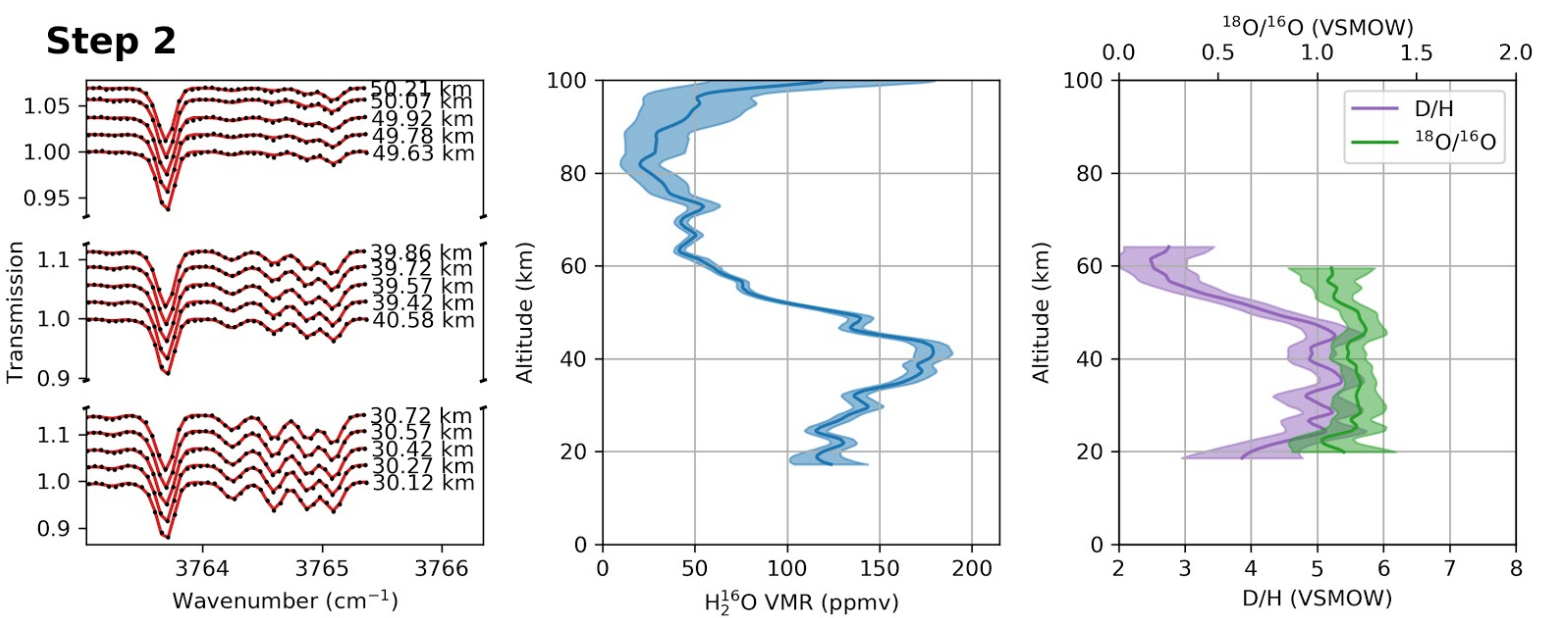

350 Figure 1: Example of ACS MIR spectra and summary of the retrieval scheme. ACS MIR spectra shown in this

351 figure was obtained in orbit 4409 (Latitude $=42^{\circ} \mathrm{S}, L_{s}=291^{\circ}$, Local time $\left.=19 \mathrm{~h}\right)$. In step 1 of the retrieval

352 scheme, pressure and temperature based on the absorption of $\mathrm{CO}_{2}$, and $\mathrm{H}_{2}{ }^{16} \mathrm{O}$ volume mixing ratio profiles are

353 retrieved from one detector row in diffraction orders 223 and 224. In step 2, spectra from five different detector

354 rows are independently used to retrieve the volume mixing ratios of $\mathrm{H}_{2}{ }^{16} \mathrm{O}, \mathrm{H}_{2}{ }^{18} \mathrm{O}$ and $\mathrm{HD}^{16} \mathrm{O}$ from the spectral

355 window in diffraction order 224, which allow the derivation of the $\mathrm{D} / \mathrm{H}$ and ${ }^{18} \mathrm{O} /{ }^{16} \mathrm{O}$ isotope ratios. 

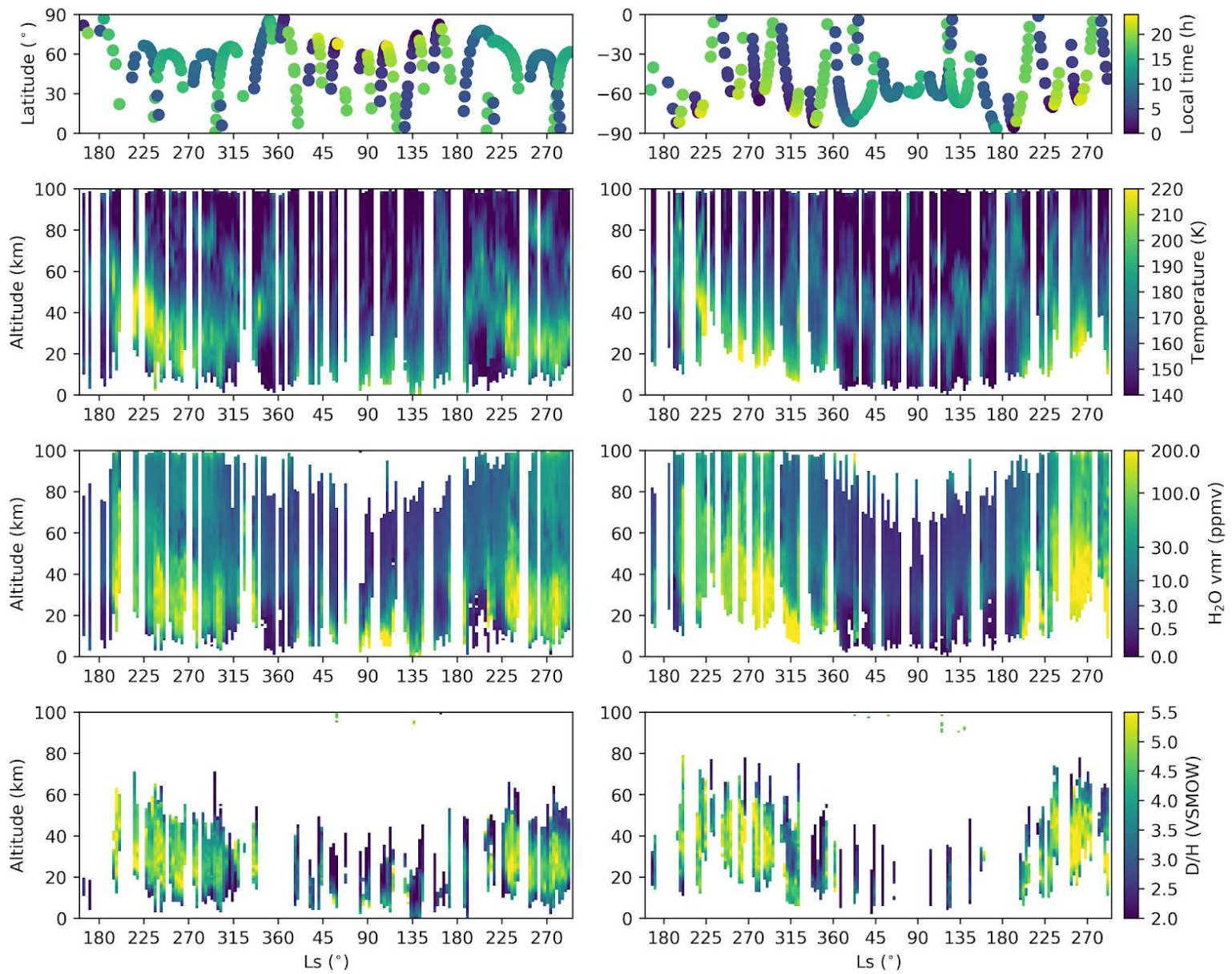

361 Figure 2: Climatology of the retrieved atmospheric parameters. The panels show the values of the retrieved

362 parameters as a function of altitude and solar longitude for the northern (left) and southern (right) hemispheres.

363 A) Distribution of ACS MIR solar occultation observations, with the local time represented by the colour bar. B)

364 Atmospheric temperature. C) Water vapour volume mixing ratio. E) D/H ratio in water vapour with

365 uncertainties lower than 1 VSMOW. 

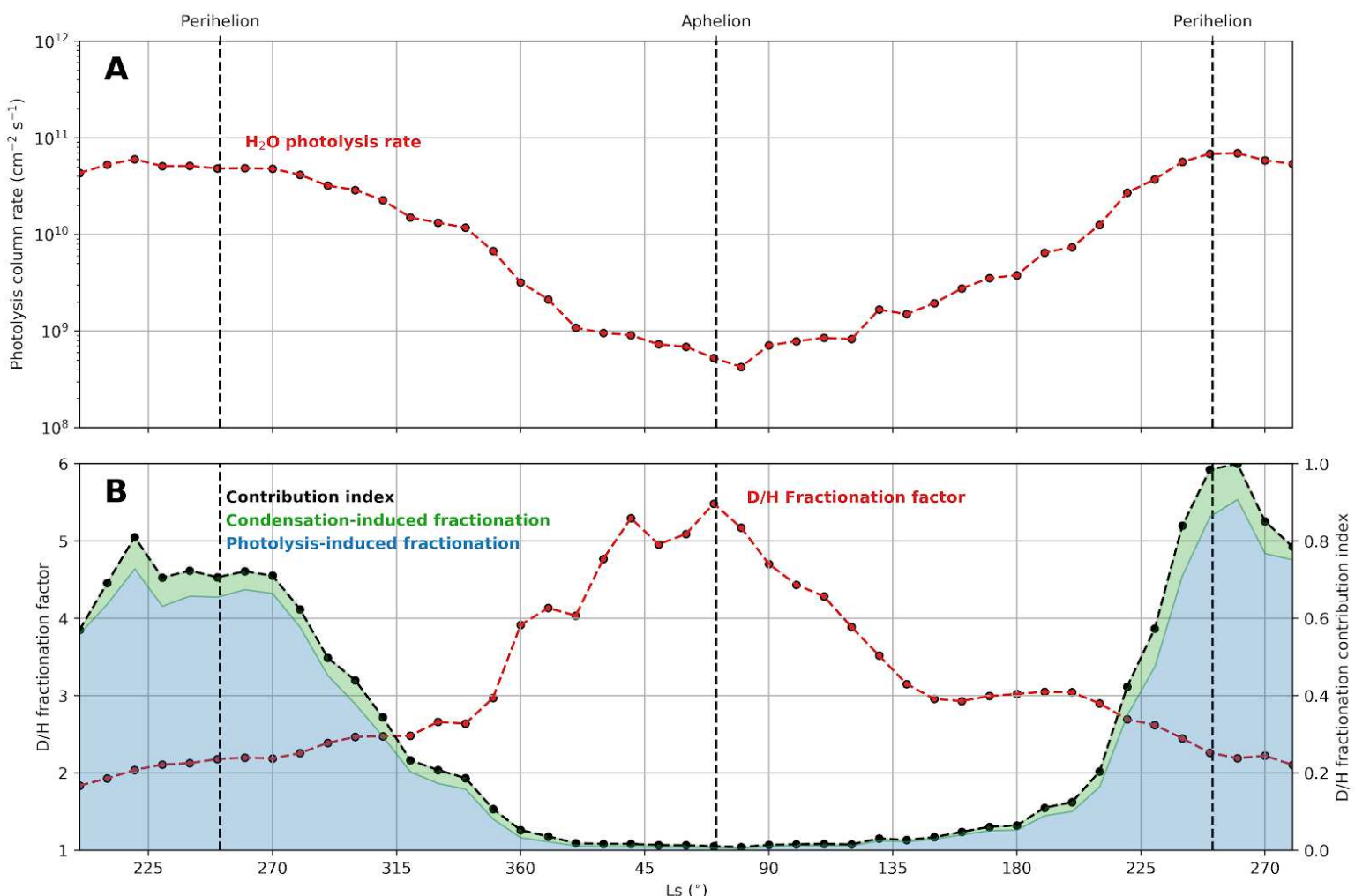

367 Figure 3: Seasonal evolution of the isotopic fractionation of D/H during the photodissociation of water

368 vapour. A) The column-integrated photolysis rate of water vapour exhibits large seasonal variations, revealing

369 the perihelion season to be dominant in the production of $\mathrm{OH}$ and $H$. B) The estimated fractionation factor

370 between the value representative of the lower atmosphere $(\mathrm{D} / \mathrm{H}=5 \mathrm{VSMOW})$ and its photodissociation products

$371\left((D / H)_{b u l k} /(D / H)_{\text {products }}\right)$ (red curve) is anti-correlated with the photolysis of water vapour, peaking near aphelion.

372 Also plotted is the contribution index (normalised photolysis rate of $\mathrm{H}_{2} \mathrm{O}$ - black line) of each point to the

373 annual average of the D/H fractionation factor, showing the prevalence of the perihelion season on the global

374 scale. The contribution of condensation-induced $\left(F_{\text {cond }}\right.$ ) and photolysis-induced fractionation ( $\left.F_{\text {photo }}\right)($ shaded

375 polygons) to the total D/H fractionation factor ( $B$, shaded polygons) demonstrate the prevalence of the latter in

376 shaping the isotopic composition of the escaping hydrogen. 


\section{ACS instrument and measurements}

382 ACS is a combination of three different infrared spectrometers: a spectrometer combining an

383 acousto-optic tunable filter (AOTF) with an echelle grating in the near infrared (NIR), an

384 echelle cross dispersion spectrometer in the middle infrared (MIR), and a Fourier Transform

385 spectrometer for the thermal infrared (TIRVIM), covering a total spectral range from 0.7 to

$38617 \mu \mathrm{m}^{26}$. ACS MIR, used in this study, counts with a novel design that allows the

387 simultaneous selection of 9 to 25 diffraction orders, achieving high resolving power

$388(\lambda / \Delta \lambda \sim 30,000)$ in a wide instantaneous spectral range $(0.15-0.3 \mu \mathrm{m})$. The selected diffraction

389 orders are projected onto a $640 \times 512$ pixel detector frame, creating a two-dimensional image

390 such that the horizontal dimension represents the spectral coordinate, while the vertical axis

391 comprises the projection of the slit for the different diffraction orders ${ }^{45}$. The projection of the

392 slit on the detector covers between 10 and 20 pixels and represents the instantaneous

393 field-of-view of the instrument $(1 \times 14 \mathrm{arcmin})$, with a vertical resolution of approximately

394150 m per pixel (see Fig. S1).

395

396 In each ACS MIR solar occultation, the Sun is observed from an altitude of $270 \mathrm{~km}$ until it is

397 concealed by the surface, accumulating the detector frames every $2.1 \mathrm{~s}$, which allows the

398 reconstruction of vertical profiles with a sampling of approximately $1-2 \mathrm{~km}$, although the

399 effective vertical resolution can be increased by combining different rows from the detector.

400 The reference solar spectrum used to derive the transmission spectra is estimated from the

401 acquisitions above $190 \mathrm{~km}$, while the observations beneath the Martian surface are used to

402 estimate the dark signal. Calibration of the transmission spectra includes the removal of the

403 dark signal, straylight and hot pixels, as well as a correction for the sub-pixel drift occurring 

due to the slightly varying thermal state of the instrument. Spectral calibration of the measurements is performed using a comparison of the solar lines with the ACE-FTS solar

406 atlas ${ }^{46}$, and then further refined using absorption lines of $\mathrm{H}_{2} \mathrm{O}$ and $\mathrm{CO}_{2}$.

407

408 Comparison between the measured and modelled transmission spectra depicted a doubling of

409 the absorption lines ${ }^{11}$, which later on was revealed to be the result of a doubled image of the

410 detector frame. The cause of this doubled-image is unknown, although it is presumably the

411 result of a partial fracture in one of the lenses broken during launch. The nature and

412 magnitude of the double image is complex, varying throughout the detector array, and

413 making a potential rectification of the fault difficult. Fig. S1 shows the spectra acquired by

414 ACS MIR when using secondary grating position 4 in different diffraction orders, situated in

415 the upper and lower parts of the detector, and in two different rows within the diffraction

416 orders. In diffraction order 217 , which is situated in the upper part of the detector, the

417 spectrum measured at the stripe centre shows absorption lines with two peaks, caused by the

418 doubling of the image. At the slit edge, the spectrum shows single peaks for each absorption

419 line instead. On the other hand, the impact of the doubling is milder for the lower part of the

420 detector frame. While the measured spectra show clear differences between the doubling at

421 the slit centre and edge in diffraction order 217 , these differences are milder for diffraction

422 order 223, which is situated at the bottom part of the detector frame.

423

424 The dataset assembled for this study includes spectra measured in diffraction orders 223 and

425224 , which are both situated at the lower part of the detector frame. Although the impact of

426 the doubled-image is expected to be small in this portion of the detector, it is accounted for in 

the analysis of the data, considering an instrument line shape (ILS) consisting of a superposition of two Gaussian functions ${ }^{11}$. In particular, the following assumptions are made 429 to create a model to fit the ILS: 1) The full-width at half-maximum (FWHM) of the two

430 Gaussian functions is the same, and constant in wavelength units; 2) The relative offset of the 431 two Gaussians is constant along the selected spectral range; 3) The relative depth of the two 432 Gaussians is linearly dependent with wavenumber. 4) The same ILS parameters apply to all 433 acquisitions made within the same solar occultation measurement.

\section{Selection of spectral range}

435 The design of the ACS MIR instrument allows the simultaneous observation of 9 to 25

436 diffraction orders with a spectral width ranging between $0.15-0.3 \mu \mathrm{m}$, within the total spectral

437 range covered by the instrument $(2.2-4.4 \mu \mathrm{m})$. The first step of the study relies on selecting

438 the spectral range most suitable for the measurements of isotopic ratios in Martian water

439 vapour, taking into account the characteristics of ACS MIR.

440 Figure S2 shows a synthetic spectrum of the Martian atmosphere covering the full spectral

441 range of ACS MIR, showing the absorption by $\mathrm{CO}_{2}$ and several isotopologues of $\mathrm{H}_{2} \mathrm{O}$. In

442 addition, the instantaneous spectral range covered by ACS MIR when using different

443 secondary grating positions is shown. This figure shows secondary grating positions $4,5,10$

444 and 11 to be the most suitable for the measurement of water vapour isotopes. However, all

445 these spectral ranges have both advantages and disadvantages:

446 - Secondary grating position $10\left(2529-2761 \mathrm{~cm}^{-1}\right)$ : Absorption by $\mathrm{HD}^{16} \mathrm{O}$ is measurable and the absorption is not contaminated by other species. However, the absence of measurable lines of $\mathrm{H}_{2}{ }^{16} \mathrm{O}$ impedes the derivation of the $\mathrm{D} / \mathrm{H}$ ratio (see Fig. S3). 
- Secondary grating position $11\left(2713-2996 \mathrm{~cm}^{-1}\right)$ : Absorption by $\mathrm{HD}^{16} \mathrm{O}$ is measurable in several diffraction orders and not contaminated by other species. $\mathrm{H}_{2}{ }^{16} \mathrm{O}$ lines are observable in diffraction order 175 , allowing the derivation of the $\mathrm{D} / \mathrm{H}$. However, the $\mathrm{H}_{2}{ }^{16} \mathrm{O}$ lines are weaker than those from $\mathrm{HD}^{16} \mathrm{O}$ and disappear at lower altitudes, limiting the vertical extent of the retrievals.

- Secondary grating position $4\left(3604-3769 \mathrm{~cm}^{-1}\right)$ : Absorption by $\mathrm{H}_{2}{ }^{16} \mathrm{O}, \mathrm{H}_{2}{ }^{18} \mathrm{O}, \mathrm{H}_{2}{ }^{17} \mathrm{O}$ and $\mathrm{HD}^{16} \mathrm{O}$ is measurable within the spectral range, enabling the derivation of the $\mathrm{H}$ and $\mathrm{O}$ isotope ratios. Most of the absorption lines are masked by the $\mathrm{CO}_{2}$ absorption, making diffraction order 224 the only suitable for isotopic studies.

- Secondary grating position $5\left(3789-3987 \mathrm{~cm}^{-1}\right)$ : Absorption by $\mathrm{H}_{2}{ }^{16} \mathrm{O}, \mathrm{H}_{2}{ }^{18} \mathrm{O}, \mathrm{H}_{2}{ }^{17} \mathrm{O}$ and $\mathrm{HD}^{16} \mathrm{O}$ is measurable within the spectral range in several diffraction orders, enabling the derivation of the $\mathrm{H}$ and $\mathrm{O}$ isotope ratios. Nevertheless, the $\mathrm{HD}^{16} \mathrm{O}$ absorption lines are weaker than those found in the other positions, limiting the accuracy and detectability of the $\mathrm{D} / \mathrm{H}$ ratio $^{11}$.

463 From this analysis, we select the ACS MIR measurements made with secondary grating

464 position 4 to perform the retrievals. The availability of $\mathrm{HD}^{16} \mathrm{O}$ and $\mathrm{H}_{2}{ }^{18} \mathrm{O}$ lines is more limited

465 than when observing using other positions, but the lines are among the strongest within ACS

466 MIR's spectral range, and observed within the same diffraction order, which reduces the

467 impact of potential systematic uncertainties from the data. In addition, this position allows the

468 simultaneous characterisation of the pressure and temperature fields, which is essential for

469 the correct characterisation of the spectroscopic parameters and the interpretation of the 470 results. 


\section{Retrieval scheme}

472 The retrieval scheme is performed in two steps. First of all, the pressure and temperature

473 profiles are retrieved from the $\mathrm{CO}_{2}$ absorption in diffraction order 223, while the vertical

474 profile of $\mathrm{H}_{2}{ }^{16} \mathrm{O}$ volume mixing ratio is retrieved from diffraction order 224. Secondly, the

475 pressure and temperature profiles are fixed, and the retrieved $\mathrm{H}_{2}{ }^{16} \mathrm{O}$ volume mixing ratio is

476 used as an a priori estimate to retrieve the volume mixing ratios of $\mathrm{H}_{2}{ }^{16} \mathrm{O}, \mathrm{H}_{2}{ }^{18} \mathrm{O}$ and $\mathrm{HD}^{16} \mathrm{O}$

477 in diffraction order 224, assuming an a priori isotopic composition of ${ }^{18} \mathrm{O} /{ }^{16} \mathrm{O}=1$ and $\mathrm{D} / \mathrm{H}=$

4785 with respect to VSMOW, and using a spectral window suitable for the derivation of the

479 isotopic ratios. All gaseous absorption is modelled using pre-computed look-up tables using

480 line-by-line modelling. The absorption of $\mathrm{CO}_{2}$ is modelled using the spectroscopic parameters

481 listed in the 2016 edition of the HITRAN database ${ }^{47}$. In the case of $\mathrm{H}_{2} \mathrm{O}$ we use

482 spectroscopic parameters suitable for a $\mathrm{CO}_{2}$-rich atmosphere ${ }^{48-51}$.

484 Pressure and temperature profiles are retrieved from the $\mathrm{CO}_{2}$ absorption under the

485 assumptions of a known $\mathrm{CO}_{2}$ volume mixing ratio, which is obtained from the Mars Climate

486 Database (MCD) ${ }^{52}$, and an atmosphere in hydrostatic equilibrium. Traditionally, this retrieval

487 technique consisted on retrieving a density profile from $\mathrm{CO}_{2}$ absorption, and deriving the

488 pressure and temperature profiles from the hydrostatic and ideal gas laws ${ }^{53,54}$. In this study,

489 the same assumptions are made, but retrieving a continuous profile of temperature and the

490 pressure at a given tangent height. The rest of the pressure levels are re-computed based on

491 the hydrostatic equation given by

$492 p(z)=p\left(z_{r}\right) \cdot \exp \left(-\int_{z_{r}}^{z} \frac{g(\bar{z}) \cdot M(\bar{z})}{T(\bar{z}) \cdot k_{B}} d \bar{z}\right)$ 
493 where $g(z)$ is the gravity, $M(z)$ is the molecular mass and $k_{B}$ is the Boltzmann constant (

$\left.494 k_{B}=1.38 \times 10^{-23} \mathrm{~J} \mathrm{~K}^{-1}\right)$. This retrieval procedure has the advantage of updating the

495 temperatures in each iteration, and consequently updating the temperature dependence of the

496 strength of the different absorption lines. In order to perform these retrievals, a spectral

497 window in diffraction order 223 between 3741 and $3753 \mathrm{~cm}^{-1}$ is selected, choosing a row

498 from the detector frame corresponding to maximum intensity, which yields the highest

499 signal-to-noise ratio (SNR).

500

501 The initial retrieval of the vertical distribution of $\mathrm{H}_{2}{ }^{16} \mathrm{O}$ volume mixing ratio is also

502 performed using the maximum-intensity row, but using a spectral window between 3759.5

503 and $3767 \mathrm{~cm}^{-1}$ in diffraction order 224 , which encompasses strong lines of $\mathrm{H}_{2}{ }^{16} \mathrm{O}$ visible up to

504 high altitudes $(>100 \mathrm{~km})$. Comparison of the retrieved $\mathrm{H}_{2}{ }^{16} \mathrm{O}$ with those derived from

505 simultaneous measurements by ACS NIR ${ }^{31}$ in $1.38 \mu \mathrm{m}$ band revealed a bias between the

506 retrieved water vapour abundance using both datasets when observing high water vapour

507 densities (see Fig. S4). This bias is presumably related to the saturation of the water vapour

508 absorption lines, which impact the sensitivity of the line along the line-of-sight. In order to

509 reconcile the retrievals from both datasets, we select a smaller spectral window (3763-3765.4

$510 \mathrm{~cm}^{-1}$ ) including weaker absorption lines of $\mathrm{H}_{2}{ }^{16} \mathrm{O}$. In this case, the retrievals are in good

511 agreement with those retrieved from ACS NIR spectra at low altitudes (see Fig. S4).

512

513 The retrieval of the $\mathrm{D} / \mathrm{H}$ and ${ }^{18} \mathrm{O} /{ }^{16} \mathrm{O}$ isotope ratios is performed using the spectral window

514 between 3763 and $3765.4 \mathrm{~cm}^{-1}$ in diffraction order 224. However, in this case, given the

515 smaller number and strength of the absorption lines, five different rows from the detector 
516 frame are independently retrieved and later combined, increasing the effective vertical

517 resolution of the measurements, as well as the confidence of the retrievals. The independent

518 retrieved profiles of $\mathrm{H}_{2}{ }^{16} \mathrm{O}, \mathrm{H}_{2}{ }^{18} \mathrm{O}$ and $\mathrm{HD}^{16} \mathrm{O}$ volume mixing ratio are combined using a

519 weighted average, in which the weights are given by the inverse of the retrieved variance at

520 each altitude $\left(\sigma(z)^{-2}\right)$, after applying a correction to mitigate the effect of the a priori

521 uncertainty in the retrieval errors ${ }^{11,55}$. The uncertainty of the weighted-average profiles is

522 calculated considering not only the retrieved uncertainties of each independent retrieval, but

523 also the dispersion of each of the independent retrieved profiles, which is considered to

524 provide a more accurate representation of the true uncertainty of the retrieval (see Fig. S5).

526 Once the vertical profiles of the $\mathrm{H}_{2}{ }^{16} \mathrm{O}, \mathrm{H}_{2}{ }^{18} \mathrm{O}$ and $\mathrm{HD}^{16} \mathrm{O}$ mixing ratios are calculated, it is

527 possible to derive the $\mathrm{D} / \mathrm{H}$ and ${ }^{18} \mathrm{O} /{ }^{16} \mathrm{O}$ isotopic ratios following

$528 D / H=\frac{1}{2} \frac{\left[H D^{16} O\right]}{\left[H_{2}^{16} O\right]}$ and ${ }^{18} O /{ }^{16} O=\frac{\left[H_{2}^{18} O\right]}{\left[H_{2}^{16} O\right]}$,

529 which are then normalised using the Vienna Standard Mean Ocean Water (VSMOW; D/H =

$5301.6 \times 10^{-4}$ and $\left.{ }^{18} \mathrm{O} /{ }^{16} \mathrm{O}=2.0 \times 10^{-3}\right)$. The uncertainties in the isotope ratios are then calculated

531 using

$532 \sigma_{D / H}=D / H \cdot \sqrt{\left(\frac{\sigma_{H D O}}{[H D O]}\right)^{2}+\left(\frac{\sigma_{H_{2}^{16 O}}}{\left[H_{2}^{16} O\right]}\right)^{2}}$ and

$533 \sigma_{{ }^{18} O /{ }^{16} O}={ }^{18} O /{ }^{16} O \cdot \sqrt{\left(\frac{\sigma_{H_{2}^{18} O}}{\left[H_{2}^{18} O\right]}\right)^{2}+\left(\frac{\sigma_{H_{2}^{16} O}}{\left[H_{2}^{16} O\right]}\right)^{2}}$.

\section{Validation of measurements and methods}

535 From the start of the science mission, comparisons between the simultaneous observations

536 made by the MIR and NIR channels have been used to validate the measurements and 
537 methods. Here, we validate the ACS MIR position 4 vertical profiles of temperature and

538 water vapour volume mixing ratio against those measured by ACS NIR, which constrain the

539 pressure and temperature profiles from the $\mathrm{CO}_{2}$ absorption band at $1.57 \mu \mathrm{m}$ and the water

540 vapour mixing ratio from the absorption band at $1.38 \mu \mathrm{m}^{31}$. As shown in Fig. S6, both

541 analyses are found to be in good agreement, increasing the confidence in the retrieved

542 profiles from both datasets.

543

544 Unfortunately, the ACS NIR channel does not include any absorption bands of the minor

545 water isotopologues (i.e. $\mathrm{H}_{2}{ }^{18} \mathrm{O}$ and $\mathrm{HD}^{16} \mathrm{O}$ ), and the retrievals of the isotope ratios cannot be

546 validated with simultaneous measurements. In order to validate these, we perform retrievals

547 of the $\mathrm{D} / \mathrm{H}$ ratio using secondary grating position 11 , using the pressure and temperature

548 fields retrieved by ACS NIR. In particular, we retrieve the $\mathrm{H}_{2}{ }^{16} \mathrm{O}$ and $\mathrm{HD}^{16} \mathrm{O}$ mixing ratios

549 from diffraction orders 175 and 162 (see Fig. S3), using spectral windows between 2932 and

$5502938 \mathrm{~cm}^{-1}$, and 2719 and $2725 \mathrm{~cm}^{-1}$, respectively. The derived vertical profiles of $\mathrm{D} / \mathrm{H}$ ratio

551 from both spectral ranges show similar behaviours, confirming and validating the retrievals

552 from secondary grating position 4 (see Fig. S7).

\section{Estimation of the average $\mathrm{D} / \mathrm{H}$ and ${ }^{18} \mathrm{O} /{ }^{16} \mathrm{O}$ isotopic ratios}

554 Understanding the variability of the isotopic ratios is essential to disentangle the values

555 inferred from localised measurements, which are subject to fractionating processes, and the

556 isotopic ratio representative of the Martian atmosphere. Figure S9 shows a histogram of the

557 measured values with uncertainties lower than $0.8 \mathrm{VSMOW}$ for the $\mathrm{D} / \mathrm{H}$ ratio, and 0.12

558 VSMOW for the ${ }^{18} \mathrm{O} /{ }^{16} \mathrm{O}$ isotope ratio, as well as their relation to other atmospheric

559 parameters. 
561 The observed values of the $\mathrm{D} / \mathrm{H}$ ratio show a large range of variability, varying from values as

562 low as 1-2 to 5-6 VSMOW, with uncertainties typically lying within 0.3-0.5 VSMOW. The

563 estimation of the $\mathrm{D} / \mathrm{H}$ ratio representative of the present-day Martian atmosphere requires the

564 subtraction of climatological effects that impact the isotopic composition at certain times and

565 locations. Climatological fractionation effects are expected to be minimum when observing

566 high temperatures and water vapour abundances, when water is fully vaporised and free from

567 condensation $^{4}$. Under these conditions, most of the observations yield D/H ratios between 4

568 and 5 VSMOW. Larger values of the D/H ratio (5-6 VSMOW) are observed in certain

569 instances, although this may simply be an artefact due to the intrinsic uncertainty of the

570 measurements $(\sigma \sim 0.4$ VSMOW), as shown in Figure 4 . Therefore, we estimate the value

571 representative of the present-day atmosphere to be $\mathrm{D} / \mathrm{H}=5.0 \pm 0.4 \mathrm{VSMOW}$.

572

573 In the case of the ${ }^{18} \mathrm{O} /{ }^{16} \mathrm{O}$ isotope ratio, the observed variations are smaller than those

574 observed in $\mathrm{D} / \mathrm{H}$, ranging from approximately 0.9 to $1.3 \mathrm{VSMOW}$, and showing no apparent

575 correlation with water abundance or temperature (see Fig. S9). With typical uncertainties

576 lying between 0.08 and $0.12 \mathrm{VSMOW}$, it is not possible to disentangle potential variations of

577 the ${ }^{18} \mathrm{O} /{ }^{16} \mathrm{O}$ isotope ratio in the Martian atmosphere from the statistical noise of the

578 instrument. From the measured ${ }^{18} \mathrm{O} /{ }^{16} \mathrm{O}$ isotope ratios throughout more than one Martian year,

579 we estimate that the ${ }^{8} \mathrm{O} /{ }^{16} \mathrm{O}$ isotope ratio representative of the Martian atmosphere is found to

580 be $1.14 \pm 0.08 \mathrm{VSMOW}$, where the uncertainty corresponds to the lower bound of the typical

581 measured uncertainties. Within the observed variations, our results are consistent with the

582 measurement made with the Sample Analysis at Mars (SAM) instrument on the Curiosity 
583 Rover, which revealed an enrichment of the ${ }^{18} \mathrm{O} /{ }^{16} \mathrm{O}$ isotope ratio of $1.084 \pm 0.01 \mathrm{VSMOW}^{3}$,

584 and with previous solar occultation measurements made with ACS MIR secondary grating

585 position 5 , which yielded a value of $1.20 \pm 0.08 \mathrm{VSMOW}^{11}$.

586

587 Estimation of the fractionation factor between water vapour and its photolysis

588 products

589 Accurate estimations of the total amount of water vapour lost throughout Martian history

590 from isotopic measurements require an understanding of the relative efficiency of the

591 different isotopologues to escape into space. This relative efficiency is represented by the

592 fractionation factor, $f$, which includes all fractionating processes from the start as $\mathrm{H}_{2} \mathrm{O}$

593 molecules, until they escape into space by either thermal or non-thermal means ${ }^{14,15,17}$. The

594 escape fractionation factor is defined as

595

$$
f=\frac{(D / H)_{\text {escape }}}{(D / H)_{\text {bulk }}}=\frac{\varphi_{D} / \varphi_{H}}{\left([H D O] / 2\left[H_{2} O\right]\right)_{\text {bulk }}}
$$

596 where $(D / H)_{\text {escape }}$ represents the ratio of escaping fluxes for deuterium $\left(\phi_{D}\right)$ and hydrogen

$597\left(\phi_{H}\right)$, and $(D / H)_{b u l k}$ represents the value of the $\mathrm{D} / \mathrm{H}$ ratio representative of the Martian lower

598 atmosphere, which we estimate to be $(D / H)_{b u l k}=5.0 \pm 0.4$ VSMOW. The first part of this

599 escape process includes the photolysis of $\mathrm{H}_{2} \mathrm{O}$, giving rise to $\mathrm{OH}$ and $\mathrm{H}$. The $\mathrm{D} / \mathrm{H}$ ratio of the

600 photolysis products may be estimated using

$$
(D / H)_{\text {products }}(z)=(D / H)_{\text {parent }}(z) \cdot \frac{J_{H D O}(z)}{J_{H 2 O}(z)}
$$


602 where $(D / H)_{\text {parent }}$ represents the $\mathrm{D} / \mathrm{H}$ ratio of the parent $\mathrm{H}_{2} \mathrm{O}$ molecules and $J_{H D O}$ and $J_{H 2 O}$ are

603 the photolysis rates of $\mathrm{HDO}$ and $\mathrm{H}_{2} \mathrm{O}$ in s${ }^{-1}$, respectively. Note that the $\mathrm{D} / \mathrm{H}$ ratio of the parent

604 molecules being photolyzed might be different from the $\mathrm{D} / \mathrm{H}$ ratio of the bulk of the

605 atmosphere if water vapour is fractionated in the lower atmosphere, leading to a localised

606 enrichment or depletion with respect to the average lower atmosphere value. Therefore, the

607 fractionation factor between the isotopic composition of the photolysis products and that of

608 the bulk of the atmosphere can be calculated as

609

$$
f^{\prime}(z)=\frac{(D / H)_{\text {products }}}{(D / H)_{\text {bulk }}}(z)=\frac{(D / H)_{\text {parent }}}{(D / H)_{\text {bulk }}}(z) \cdot \frac{J_{H D O}}{J_{H 2 O}}(z) .
$$

610 Therefore, it is the combination of two factors:

611 - The fractionation between the $\mathrm{D} / \mathrm{H}$ ratio of the atmospheric bulk representative of the

612 Martian lower atmosphere, and the $\mathrm{D} / \mathrm{H}$ ratio of the parent $\mathrm{H}_{2} \mathrm{O}$ molecules, which

613 might be subject to fractionation processes occurring in the lower atmosphere. Given

614 that the observed variations in the $\mathrm{D} / \mathrm{H}$ ratio in $\mathrm{H}_{2} \mathrm{O}$ appear to be consistent with the

615 expectations from condensation-induced fractionation, this factor represents the effect

616 that condensation processes have in fractionating the isotopic composition between

617 the bulk and the photolysis products, and is given by

$$
f_{\text {cond }}^{\prime}(z)=\frac{(D / H)_{\text {parent }}}{(D / H)_{\text {bulk }}}(z)
$$

619 - The fractionation inherent in the photolysis of $\mathrm{H}_{2} \mathrm{O}$, which differentiates between the $\mathrm{H}_{2} \mathrm{O}$ and $\mathrm{HDO}$ because of their different ultraviolet cross sections ${ }^{21}$ (see Fig. S10). Therefore, the fractionation factor inherent in the photolysis mechanism is given by 


$$
f_{\text {photo }}^{\prime}=\frac{J_{H D O}}{J_{H 2 O}}(z)
$$

623 Similarly, one may estimate the ratio of the $\mathrm{D} / \mathrm{H}$ representative of the atmospheric bulk and

624 the $\mathrm{D} / \mathrm{H}$ ratio in the photolysis products using

625

$$
F^{\prime}(z)=\frac{(D / H)_{\text {bulk }}}{(D / H)_{\text {products }}}=\frac{1}{f^{\prime}(z)}=F_{\text {cond }}^{\prime}(z) \cdot F_{\text {photo }}^{\prime}(z)=\frac{(D / H)_{\text {bulk }}}{(D / H)_{\text {parent }}}(z) \cdot \frac{J_{H 2 O}}{J_{H D O}}(z)
$$

626 In order to estimate the efficiency of these processes to fractionate the isotopes during their

627 photodissociation, the absorption cross-sections of $\mathrm{H}_{2} \mathrm{O}$ and $\mathrm{HDO}$ are implemented in the

628 photolysis model of the LMD-GCM ${ }^{17,39}$. The middle panel in Fig. S10 shows the photolysis

629 rates of $\mathrm{H}_{2} \mathrm{O}$ and $\mathrm{HDO}$ calculated for four solar zenith angles $\left(\mathrm{SZA}=0^{\circ}, 30^{\circ}, 60^{\circ}, 85^{\circ}\right)$, and

630 at a Sun-Mars distance of 1.52 astronomical units (AU). At high altitudes, the photolysis rates

631 of $\mathrm{HDO}$ and $\mathrm{H}_{2} \mathrm{O}$ are dominated by the absorption at wavelengths $\lambda<180 \mathrm{~nm}$, which exhibit

632 similar cross-sections, leading to little fractionation. At lower altitudes, the absorption by $\mathrm{CO}_{2}$

633 becomes important, impeding photons with $\lambda<180 \mathrm{~nm}$ to penetrate to the lower altitudes.

634 Instead, the photolysis of $\mathrm{H}_{2} \mathrm{O}$ and $\mathrm{HDO}$ at lower altitudes is driven by photons with $\lambda>180$

$635 \mathrm{~nm}$, which yield lower photolysis rates due the lower absorption cross-section at these

636 wavelengths, but higher fractionation between the two isotopologues.

637 In order to get an insight into the importance of seasonal effects on the photolysis of water

638 and its isotopic fractionation, the photolysis rates from the model at $\mathrm{SZA}=60^{\circ}$, are scaled to

639 the relevant Sun-Mars distance, and multiplied by the water vapour number densities

640 retrieved from the ACS MIR spectra during the summer seasons in the southern and northern

641 hemispheres (see upper panels in Fig. S11). These estimated dissociation rates show very

642 different seasonal behaviours. During the SH summer, the stronger Hadley circulation allows 
643 water to expand into the middle atmosphere in both hemispheres, where photolysis increases,

644 reaching a maximum of $\mathrm{H}_{2} \mathrm{O}$ dissociation rates at approximately $50 \mathrm{~km}$ in the $\mathrm{SH}\left(10^{4}-10^{5}\right.$

$\left.645 \mathrm{~cm}^{-3} \mathrm{~s}^{-1}\right)$, and at about $40 \mathrm{~km}$ in the $\mathrm{NH}\left(10^{3}-10^{4} \mathrm{~cm}^{-3} \mathrm{~s}^{-1}\right)$. On the other hand, during the NH

646 summer, the lower altitude of the hygropause confines water vapour to the near-surface,

647 where photolysis is very inefficient, yielding maximum dissociation rates at $10 \mathrm{~km}\left(10^{3} \mathrm{~cm}^{-3}\right.$

$648 \mathrm{~s}^{-1}$ ). The column-integrated photolysis rates are shown in the top panels of Figure S12 for the

649 perihelion and aphelion seasons observed with ACS MIR. These calculations evidence the

650 prevalence of the perihelion season for the dissociation of water, with rates between 10 and

651100 times higher than those found during aphelion.

652 The lower panels in Figure $\mathrm{S} 11$ show the fractionation factors $F^{\prime}$ associated with

653 condensation-induced and photolysis-induced fractionation. It is shown that during the

654 perihelion season, condensation-induced fractionation is not effective at $50 \mathrm{~km}\left(F^{\prime}{ }_{\text {cond }} \sim 1\right)$,

655 where the dissociation rates peak. At this altitude, the photolysis-induced fractionation factor

$656\left(F^{\prime}{ }_{\text {photo }}\right)$ is between 2 and 2.5 , meaning that the photolysis products will be depleted in $\mathrm{D} / \mathrm{H}$

657 by a factor of 2-2.5 with respect to the average $\mathrm{D} / \mathrm{H}$ of water vapour in the lower atmosphere.

658 During the aphelion season, photodissociation of water vapour peaks closer to the surface,

659 and both condensation-induced and photolysis-induced fractionation become more important.

660 Similarly, the lower panels in Figure S11 show the fractionation factors integrated over the

661 column. However, while the calculation of the photolysis-induced column-integrated

662 fractionation factor can be performed using all altitudes, the condensation-induced

663 fractionation factor can just be calculated using the altitudes at which the measurements are

664 sensitive to HDO, and missing part of the column. Therefore, the condensation-induced 
665 fractionation factor is just shown when the column-integrated photolysis rates where the

666 measurements are sensitive to HDO (yellow points in top panels of Fig. S12) are at least 75\%

667 of those using all altitudes (black points in top panels of Fig. S12). The results show a higher

668 fractionation factor during the aphelion season by both photolysis-induced and

669 condensation-induced fractionation, as compared to the perihelion season. However, even

670 during aphelion, when the role of condensation-induced fractionation becomes more

671 important, it does not exceed the role of photolysis-induced fractionation. Besides, when

672 taking into account that the contribution of each data point to the annual average is

673 proportional to the photolysis rate (see Fig. 3B), it is clear that the annual average

674 fractionation factor $F^{\prime}$ will be heavily weighted towards the perihelion season, when most of

675 the photodissociation of water vapour molecules occurs.

676 In order to calculate the seasonal evolution of the column-integrated photolysis rates and

677 fractionation factor (see Fig. 3), these are binned in $\mathrm{L}_{\mathrm{s}}$ with a step of $10^{\circ}$. In order to obtain

678 averages of the fractionation factor over latitude, we calculate a contribution index $(C I)$,

679 which is equivalent to the photolysis rate, but multiplied by a normalising factor to match its

680 maximum with unity. The averages of the fractionation factors are then calculated using the

681 contribution index as a weight. In order to visualise the relative role of photolysis-induced

682 fractionation and condensation-induced fractionation in Figure 3, we shade the areas in each

$683 \mathrm{~L}_{\mathrm{s}}$ bin corresponding to

$684 C I_{\text {photo }}=C I \cdot \frac{\left(F_{\text {photo }}^{\prime}-1\right)}{\left(F_{\text {photo }}^{\prime}+F_{\text {cond }}^{\prime}-2\right)}$ and $C I_{\text {cond }}=C I \cdot \frac{\left(F_{c o n d}^{\prime}-1\right)}{\left(F_{\text {photo }}^{\prime}+F_{\text {cond }}^{\prime}-2\right)}$. 
686 Similarly, as for $\mathrm{HDO}$, the $\mathrm{H}_{2}{ }^{18} \mathrm{O}$ molecules are expected to have a different $\mathrm{UV}$ absorption

687 cross-section than the $\mathrm{H}_{2}{ }^{16} \mathrm{O}$ ones, which can impact the isotope composition of the 688 dissociation products of water vapour and the efficiency of ${ }^{18} \mathrm{O}$ to reach the upper 689 atmosphere. To our knowledge, there are no available cross-sections for $\mathrm{H}_{2}{ }^{18} \mathrm{O}$. However, 690 theoretical methods ${ }^{43}$ to quantify the photo-induced isotopic fractionation predict most 691 noticeable differences in the absorption cross-sections of $\mathrm{H}_{2}{ }^{18} \mathrm{O}$ and $\mathrm{H}_{2}{ }^{16} \mathrm{O}$ for wavelengths $\lambda$ $692>180 \mathrm{~nm}$, similar to the $\mathrm{H}_{2} \mathrm{O}-\mathrm{HDO}$ dichotomies (see Fig. S10). However, while the 693 cross-section of $\mathrm{H}_{2} \mathrm{O}$ is about $60 \%$ higher than that of HDO for $\lambda>180 \mathrm{~nm}$, it is only about $6942.5 \%$ higher than that of $\mathrm{H}_{2}{ }^{18} \mathrm{O}$. If considering that most of the dissociation of water occurs 695 during the perihelion season between $40-60 \mathrm{~km}$, while $\mathrm{H}_{2}{ }^{16} \mathrm{O}$ molecules are about 2-2.5 times 696 more efficiently dissociated than the $\mathrm{HD}^{16} \mathrm{O}$ ones, they will be just about $1.08-1.10$ times 697 more efficiently dissociated than the $\mathrm{H}_{2}{ }^{18} \mathrm{O}$ ones. This means that the efficiency of ${ }^{18} \mathrm{O}$ to be 698 transferred to lighter molecules is about 24 times higher than that of deuterium. 


\section{Supplementary Figures}
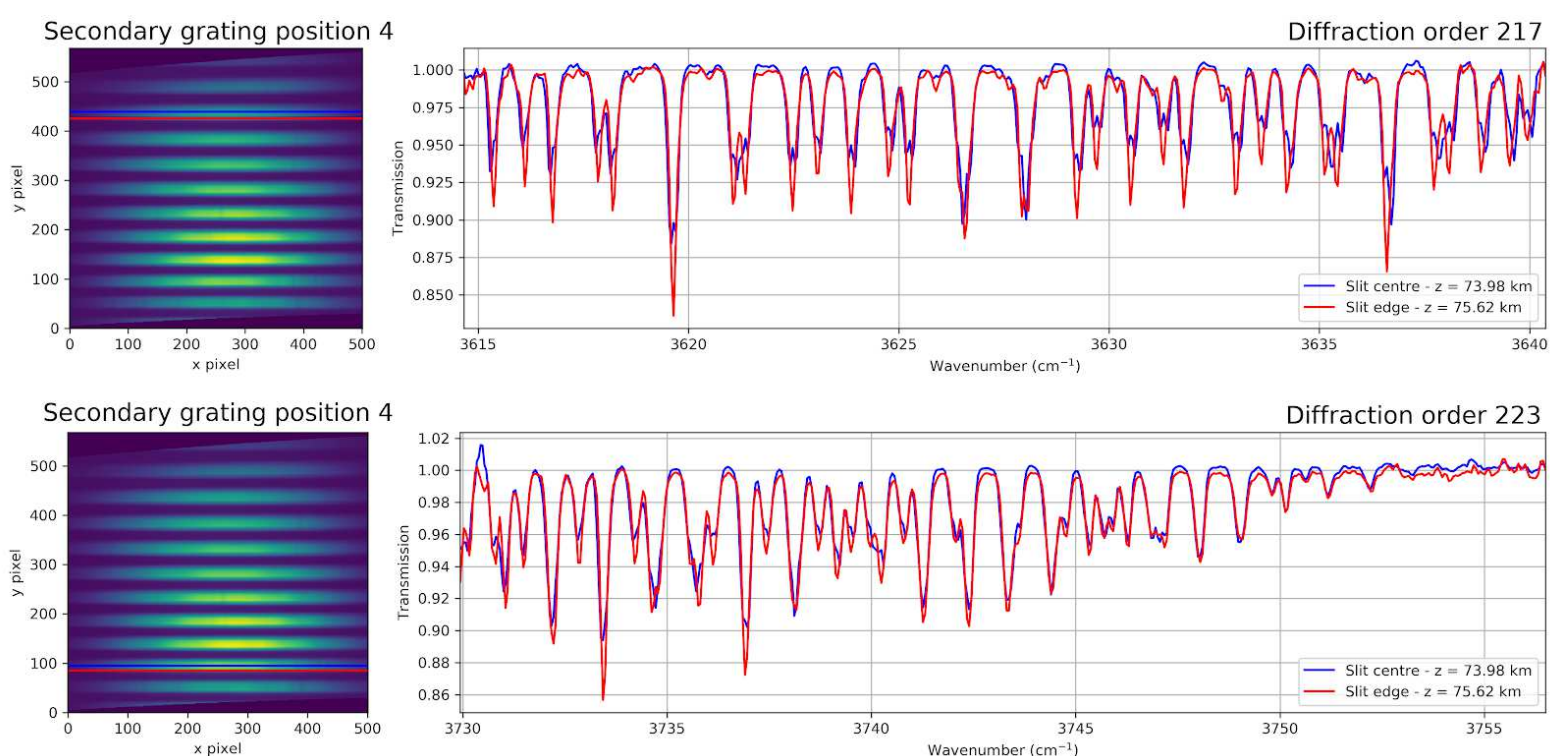

702 Figure S1: ACS MIR data and impact of doubled image to the spectra. The left panels show the measured

703 detector frames highlighting the rows corresponding to the maximum intensity (blue) and the slit edge (red) in

704 diffraction orders 217 and 223, whose corresponding spectrum is shown in the right panels.

705

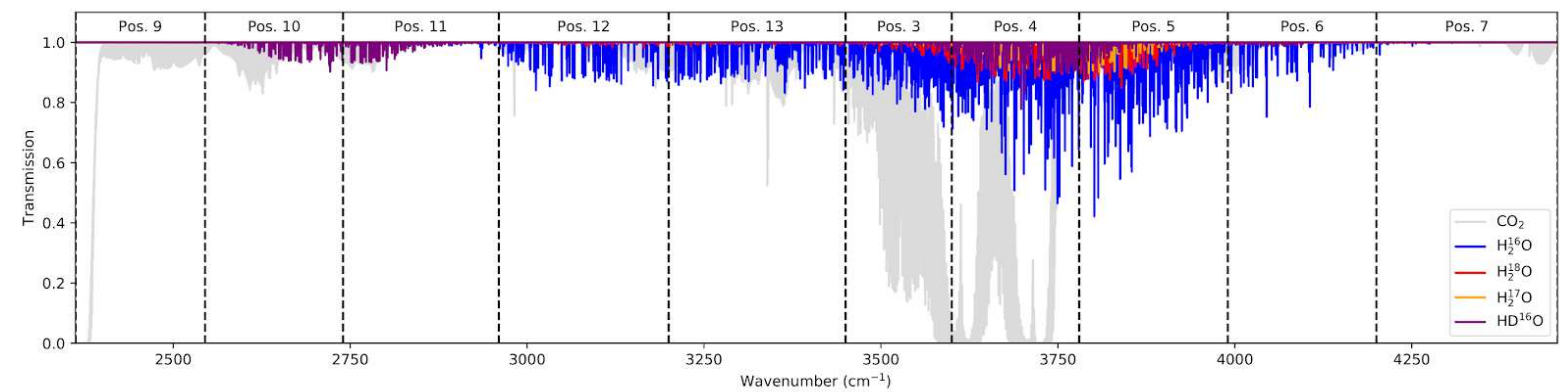

706 Figure S2: Synthetic transmission spectrum of the Martian atmosphere within the spectral range of ACS

707 MIR. The spectra was calculated using an instrument lineshape described by a Gaussian function with FWHM

708 of $0.15 \mathrm{~cm}^{-1}$, and shows the instantaneous spectral range covered by ACS MIR when using different secondary

709 grating positions. The contribution by $\mathrm{CO}_{2}$ and different isotopologues of $\mathrm{H}_{2} \mathrm{O}$ is shown in different colours,

710 following the legend. 

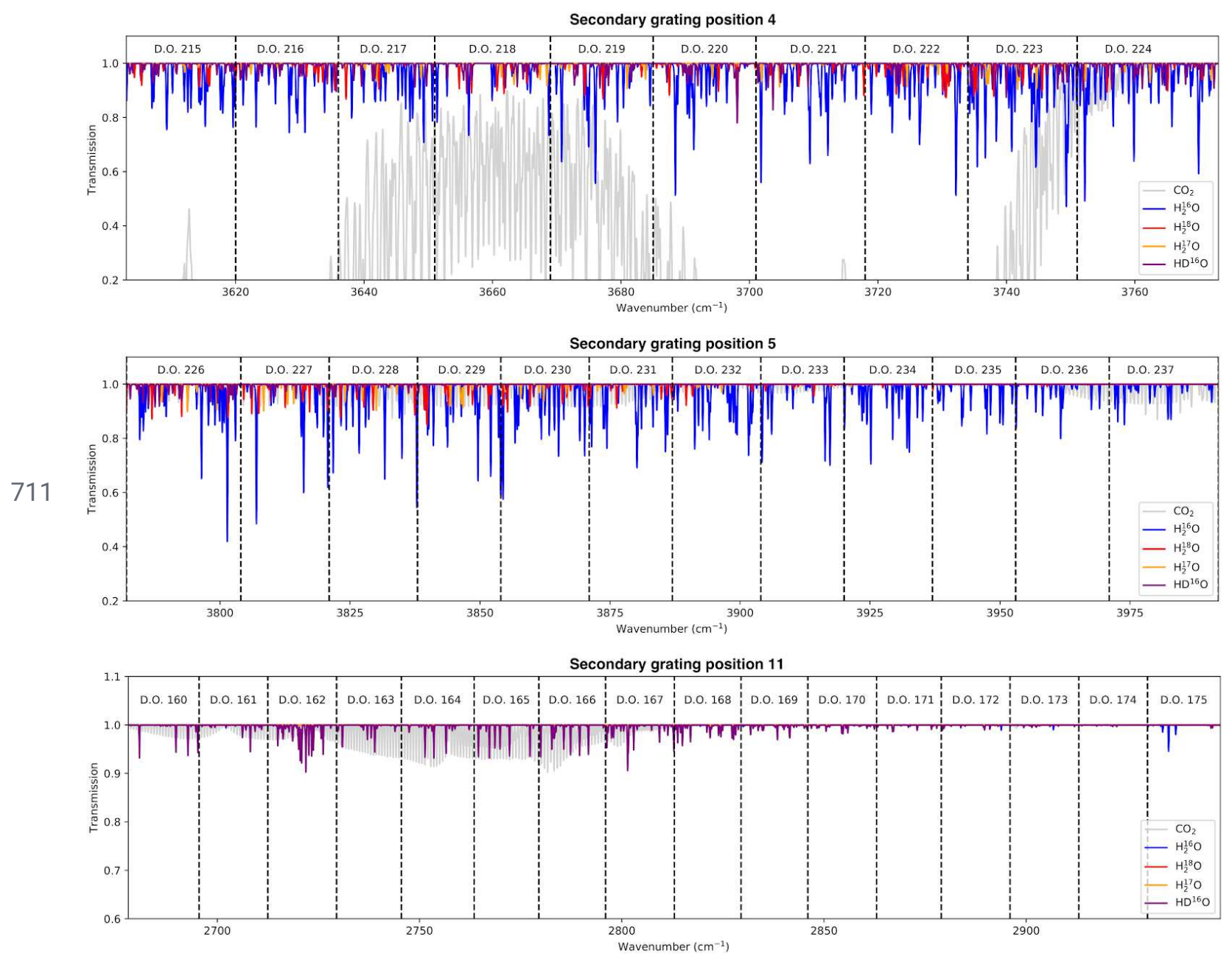

712 Figure S3: Synthetic transmission spectrum of the Martian atmosphere within the instantaneous spectral

713 range covered by ACS MIR when observing with secondary grating positions 4, 5 and 11. The spectra was

714 calculated using an instrument lineshape described by a Gaussian function with FWHM of $0.15 \mathrm{~cm}^{-1}$, and shows

715 the spectral range of the different diffraction orders acquired by ACS MIR when observing with secondary

716 grating positions 4, 5 and 11. The contribution by $\mathrm{CO}_{2}$ and different isotopologues of $\mathrm{H}_{2} \mathrm{O}$ is shown in different

717 colours, following the legend. 

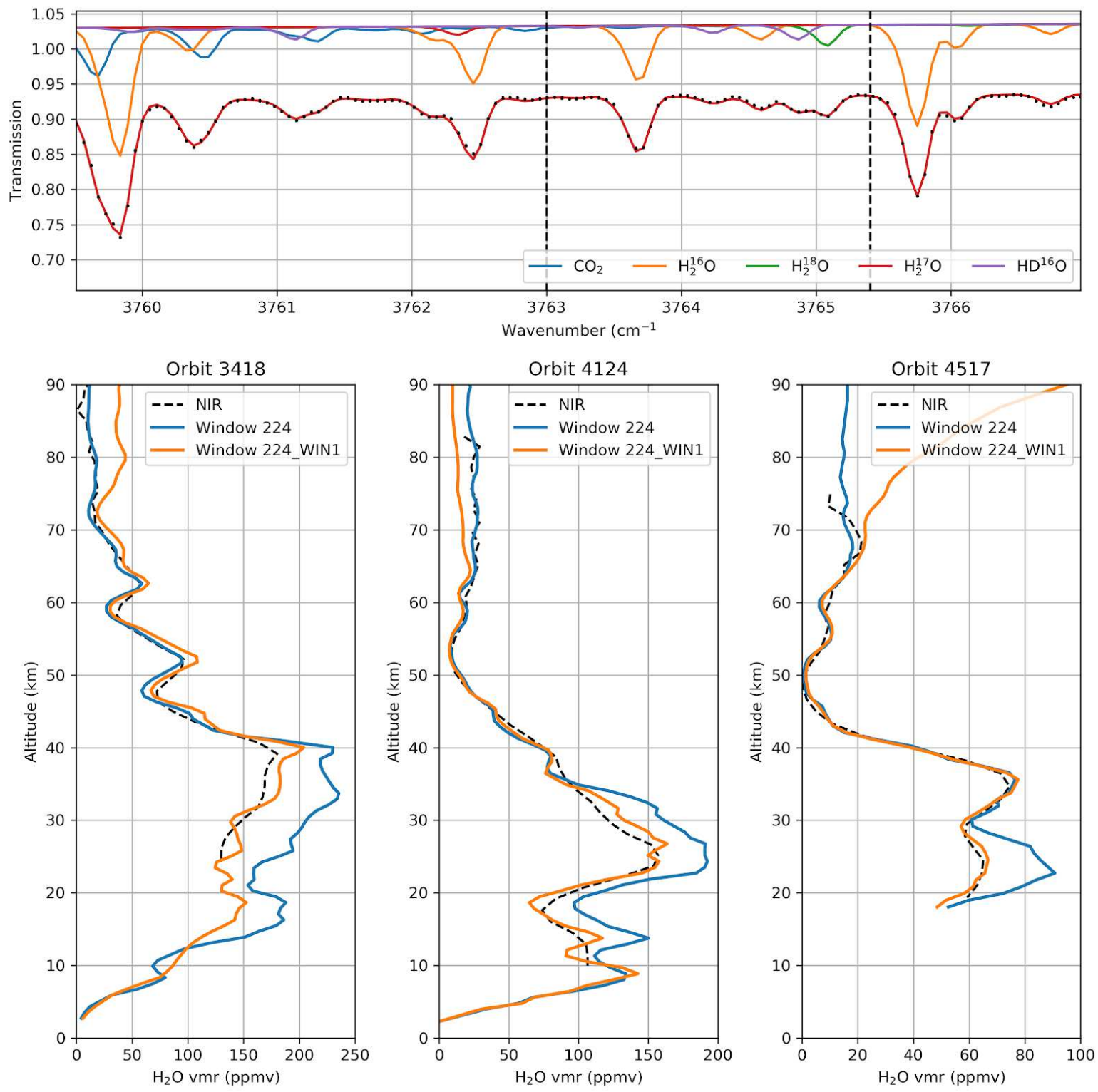

720 Figure S4: Characterising biases in the retrievals by comparing with simultaneous ACS NIR measurements.

721 The top panel shows an ACS MIR transmission spectrum (black dots), the best fit to the data (red line), as well

722 as the contribution from different gases to the spectra, following the different colours shown on the legend. The

723 lower three panels show the retrieved profiles from ACS NIR spectra (black dashed lines - Fedorova et al. ${ }^{31}$ ), as

724 well as the retrieved profiles from ACS MIR when using the whole spectral window shown in the top panel (blue

725 lines) and the spectral range shown between the black dashed lines in the top panel (orange lines). The three

726 observations shown here correspond to the observations made during orbits $3418\left(\right.$ Lat $=50^{\circ} \mathrm{N}, L_{s}=240^{\circ}$, Local

727 time $=16 \mathrm{~h}), 4124\left(\right.$ Lat $=49^{\circ} \mathrm{N}, \mathrm{L}_{s}=276^{\circ}$, Local time $\left.=8 \mathrm{~h}\right)$ and $4517\left(\right.$ Lat $=55^{\circ} \mathrm{N}, \mathrm{L}_{s}=296^{\circ}$, Local time $\left.=8 \mathrm{~h}\right)$. 

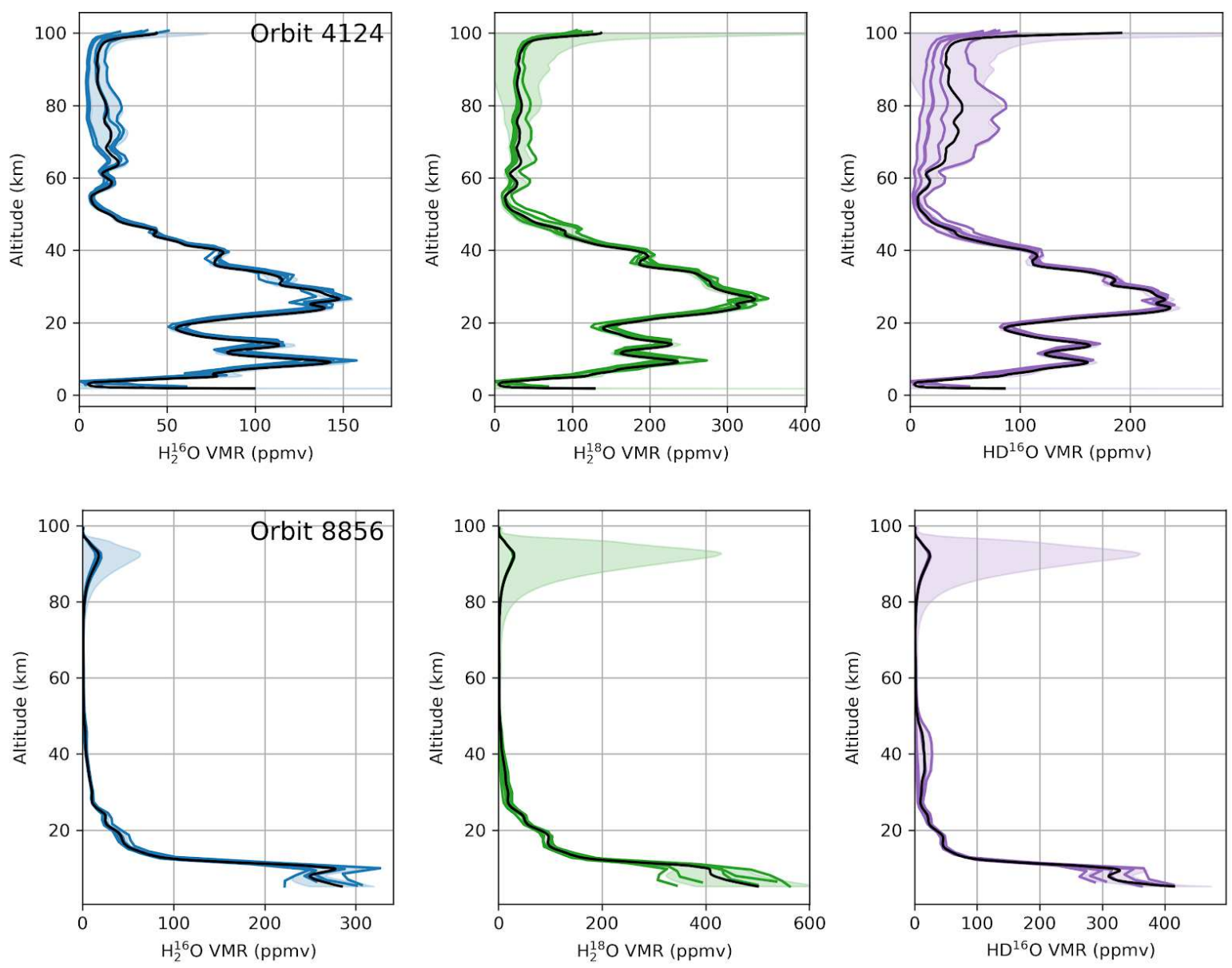

\section{Figure S5: Calculation of the averaged profiles and uncertainties in the combination from several detector}

730 rows. The different panels show the vertical profiles of $\mathrm{H}_{2}{ }^{16} \mathrm{O}, \mathrm{H}_{2}{ }^{18} \mathrm{O}$ and $\mathrm{HD}^{16} \mathrm{O}$ retrieved independently from

731 several detector rows. The uncertainties in the weighted-averaged profiles (black lines) are calculated using the

732 maximum between the propagation of errors from the different profiles and the dispersion from the independent

733 profiles from the mean. The profiles on the top panels correspond to the observation made in orbit 4124 (Lat $=$

$73449^{\circ} \mathrm{N}, L_{s}=276^{\circ}$, Local time $\left.=8 h\right)$ and the ones at the bottom to the observation made in orbit 8856 (Lat $=$

$73566^{\circ} \mathrm{N}, L_{s}=108^{\circ}$, Local time $\left.=0 h\right)$. 

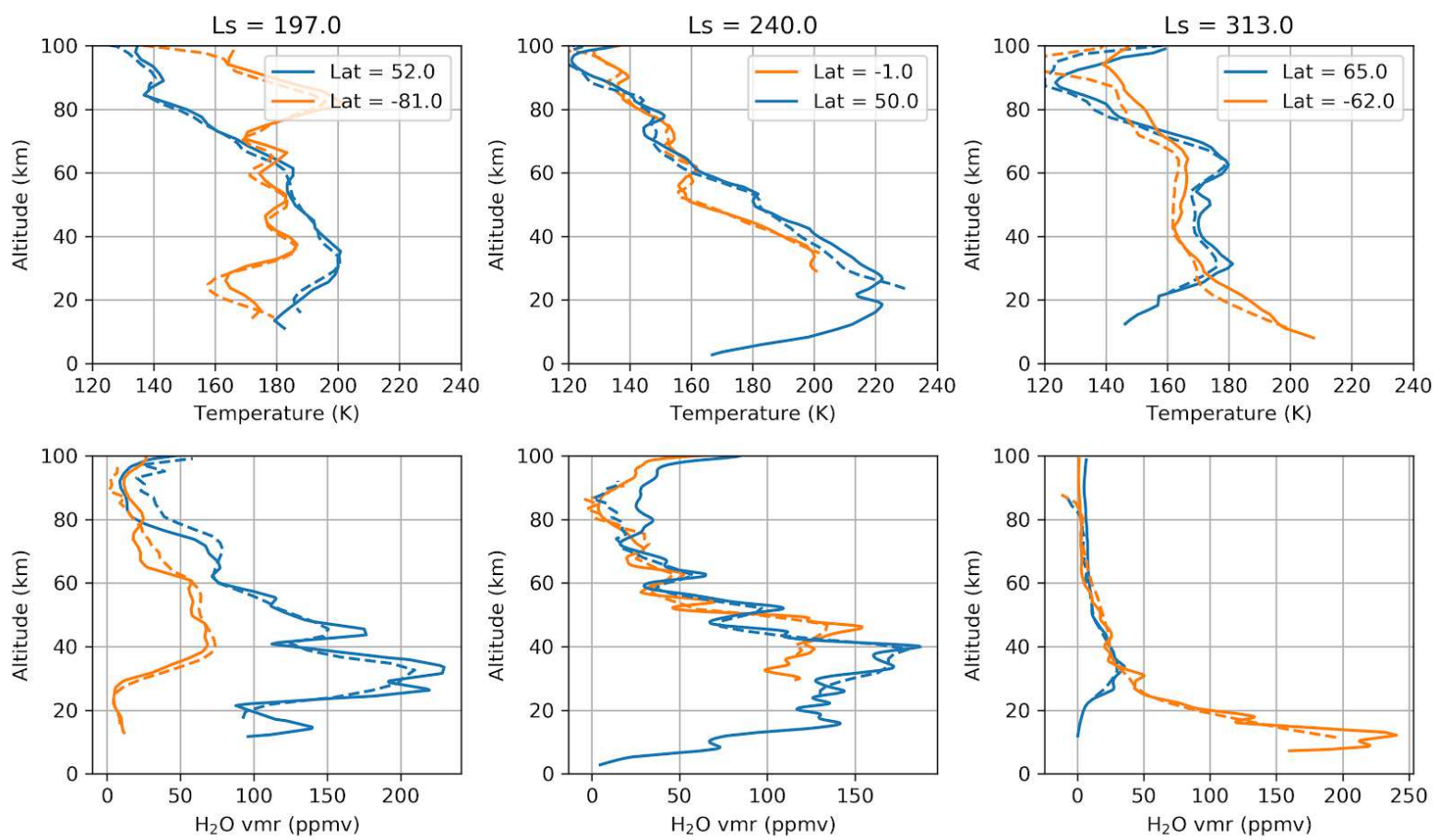

738 Figure S6: Validation of the retrieved vertical profiles of temperature and water vapour mixing ratio from

739 ACS MIR and ACS NIR. The different panels show the retrieved profiles of temperature and water vapour

740 volume mixing ratio from simultaneous observations made by ACS MIR (solid lines - this study) and ACS NIR

741 (dashed lines - Fedorova et al. ${ }^{31}$ ) in different latitudes and seasons. 

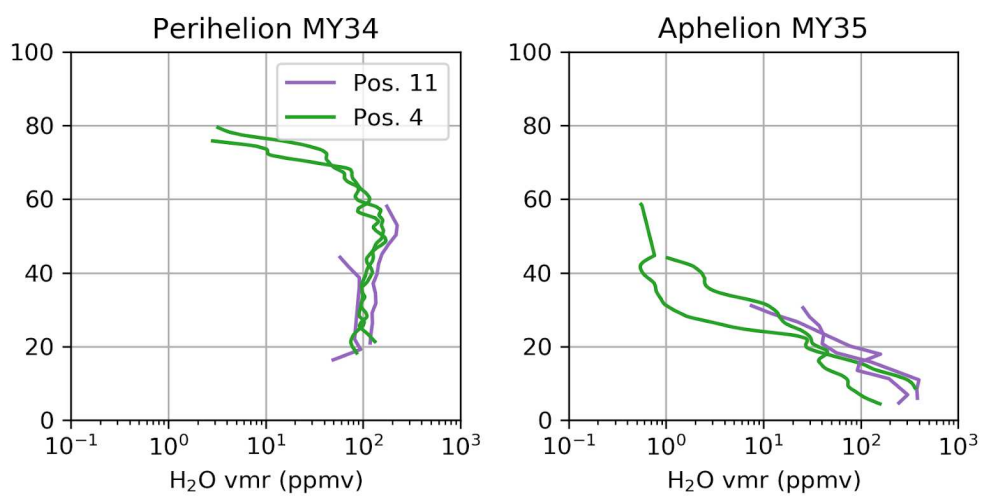

742
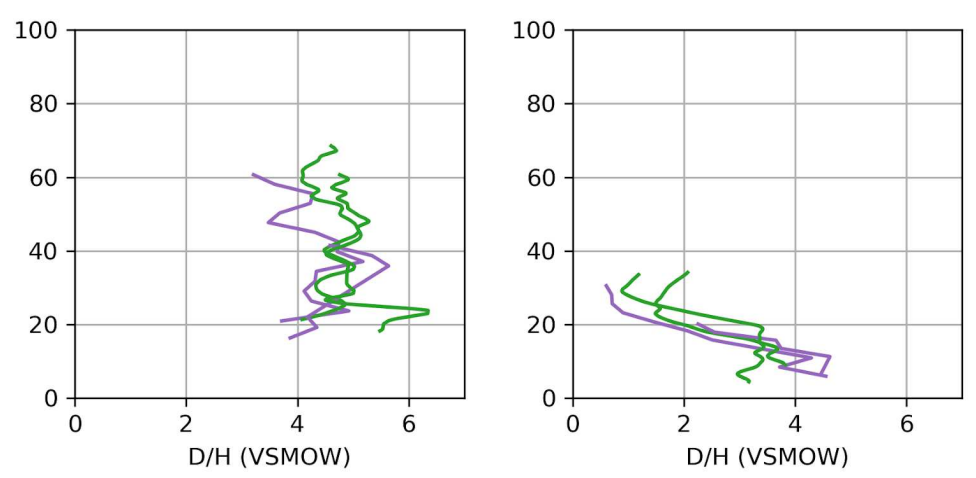

743 Figure S7: Validation of the retrieved vertical profiles of D/H using ACS MIR observations with secondary

744 grating positions 4 and 11. The different panels show the retrieved profiles of water vapour mixing ratio and

745 D/H ratio for observations taken during the perihelion season of MY34 and the aphelion season of MY35 when

746 observing with secondary grating positions 4 (green) and 11 (purple). 

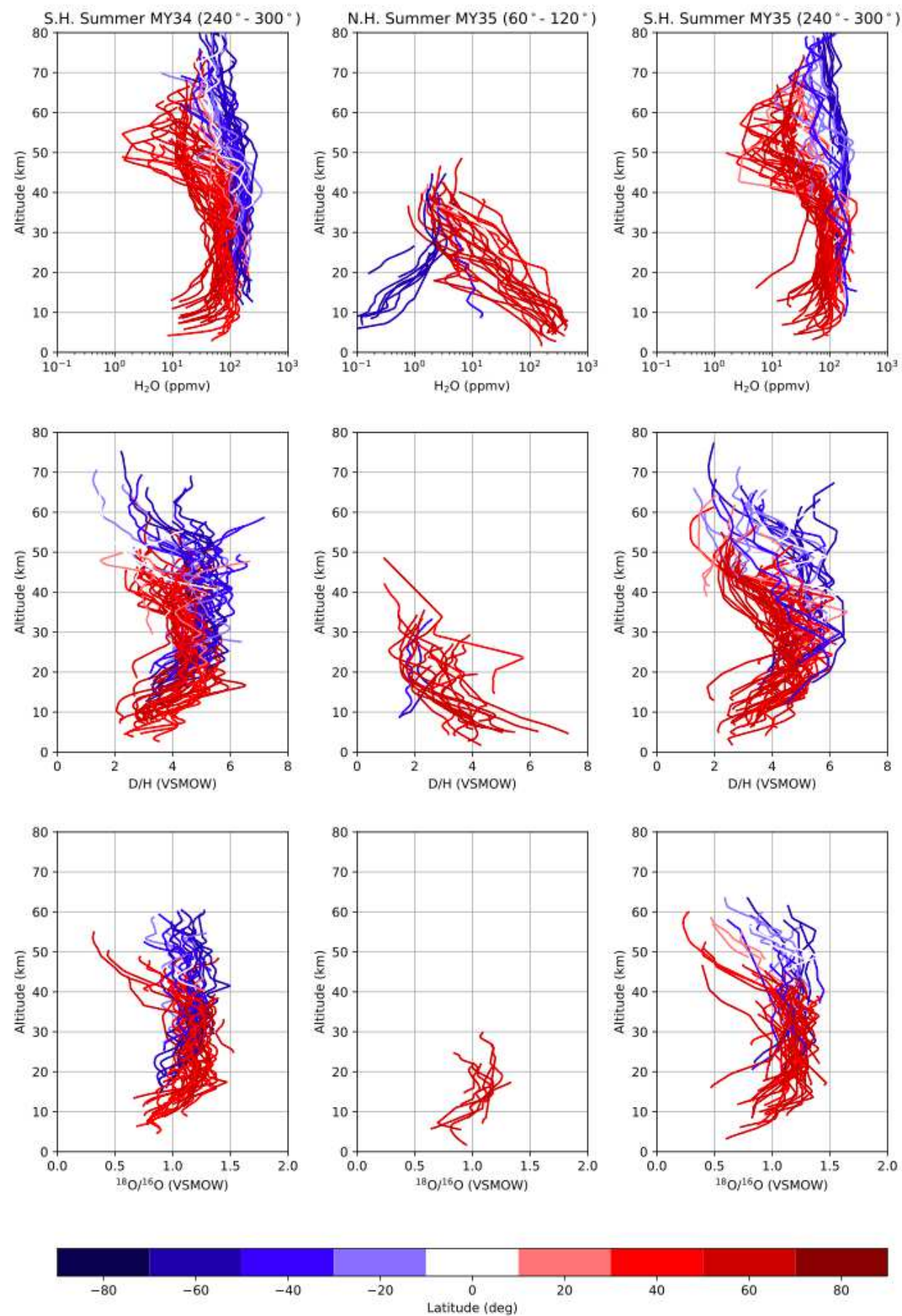

749 Figure S8: Evolution of the water vapour mixing ratio and the $\mathrm{D} / \mathrm{H}$ and ${ }^{18} \mathrm{O} /{ }^{16} \mathrm{O}$ isotopic ratios in the

750 perihelion and aphelion seasons of MY34 and MY35. The different panels show the retrieved profiles

751 separated in different seasons, with the colour of the lines representing the latitude of the observations. For the 752 clarity of the figure, only the points with uncertainties of $\mathrm{D} / \mathrm{H}<1 \mathrm{VSMOW}$ and ${ }^{18} \mathrm{O} /{ }^{16} \mathrm{O}<0.13 \mathrm{VSMOW}$ are 753 shown 

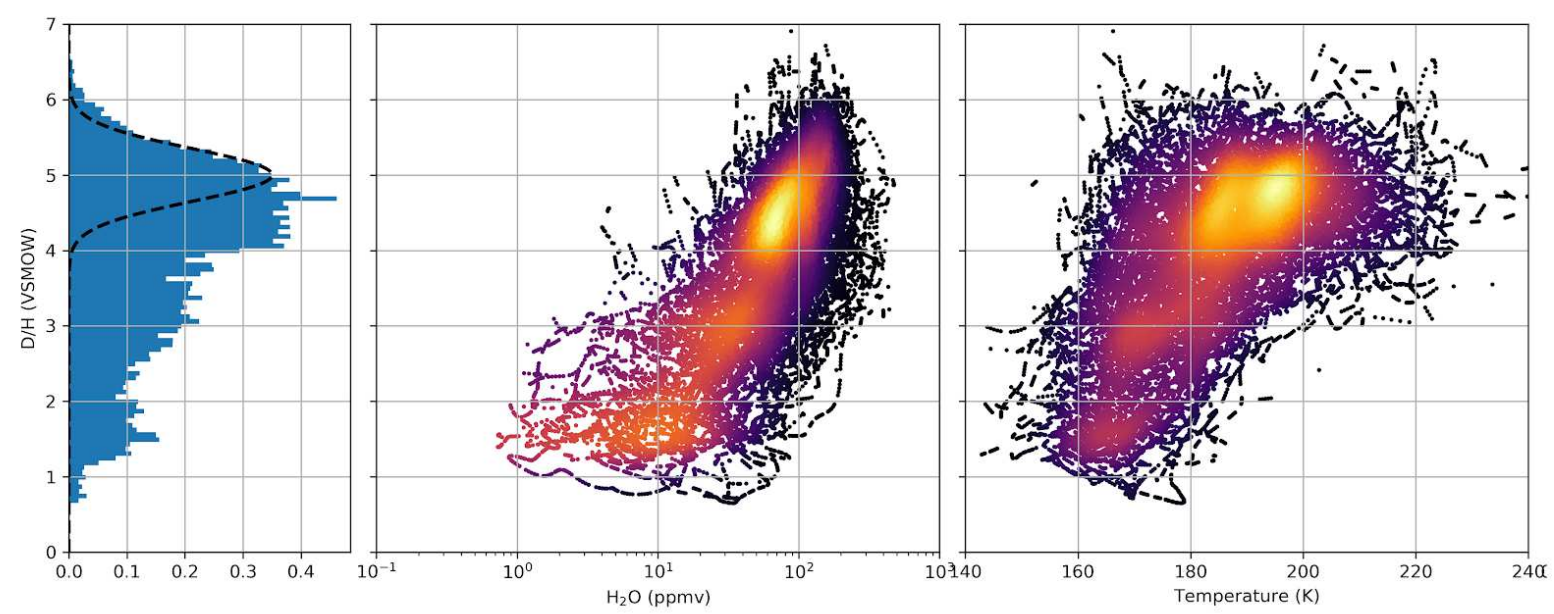

754
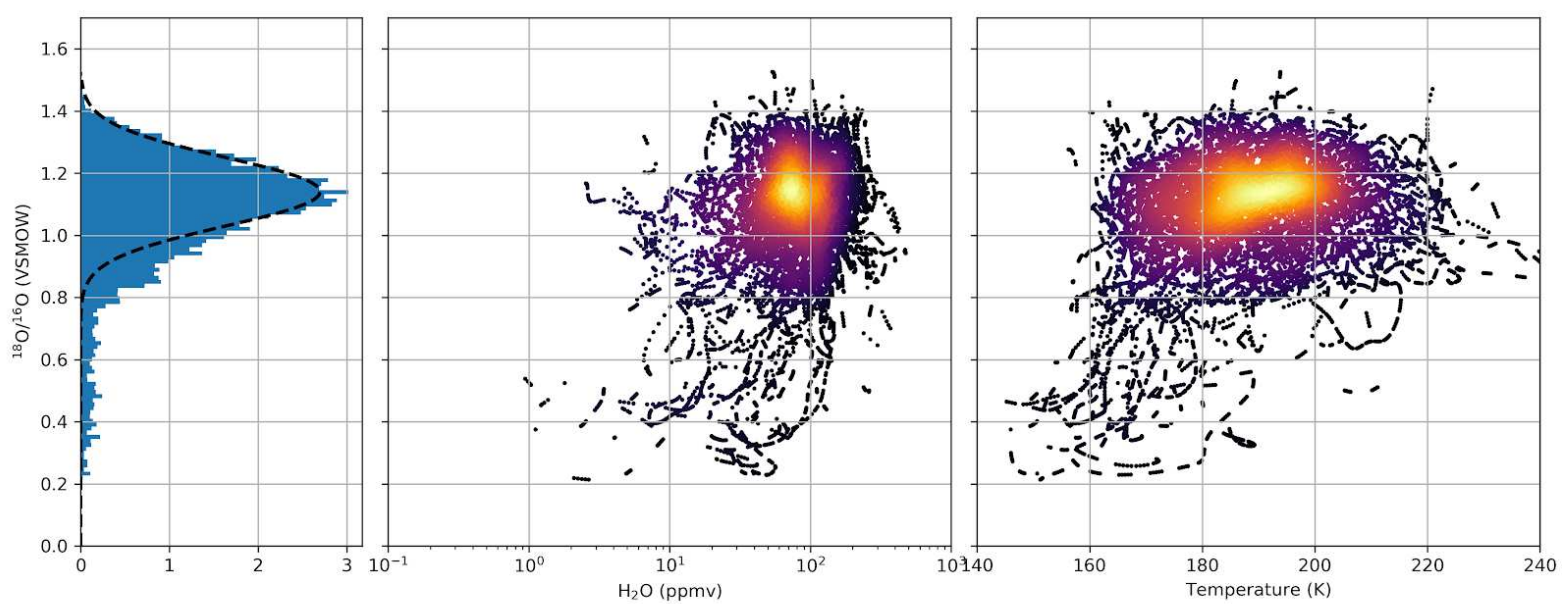

755 Figure S9: Histogram of the measured $\mathrm{D} / \mathrm{H}$ and ${ }^{18} \mathrm{O} /{ }^{16} \mathrm{O}$ isotope ratios, as well as their relation with the water

756 vapour mixing ratio and temperature. Only the points with uncertainties of $\mathrm{D} / \mathrm{H}<1 \mathrm{VSMOW}$ and ${ }^{18} \mathrm{O} /{ }^{16} \mathrm{O}<$

757 0.13 VSMOW are shown. The black dashed lines on the histogram plots represent typical measurement

758 uncertainties, centred at $\mathrm{D} / \mathrm{H}=5 \pm 0.4 \mathrm{VSMOW}$ and ${ }^{18} \mathrm{O} /{ }^{16} \mathrm{O}=1.14 \pm 0.11 \mathrm{VSMOW}$. The colour of the points on

759 the plots in the middle and right columns represents the density of measured points. 

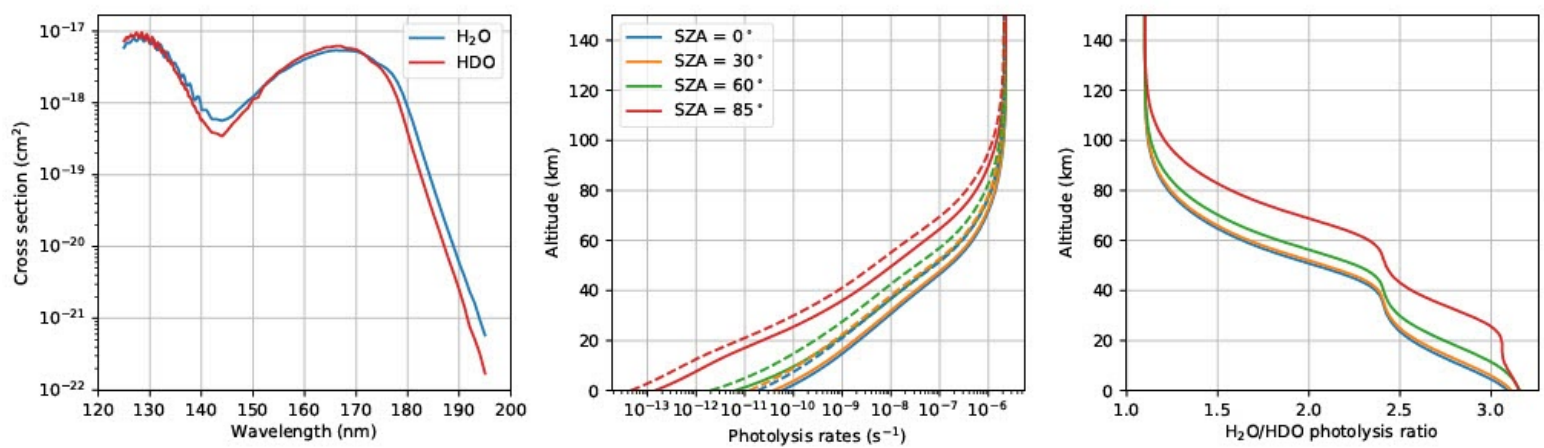

762 Figure S10: Calculation of the $\mathrm{H}_{2} \mathrm{O}$ and $\mathrm{HDO}$ photolysis rates with the photolysis code of the LMD-GCM${ }^{37}$.

763 Left) $\mathrm{UV}$ absorption cross-sections of $\mathrm{H}_{2} \mathrm{O}$ and $\mathrm{HDO}$. Middle) Photolysis rates of $\mathrm{H}_{2} \mathrm{O}$ (solid) and $\mathrm{HDO}$

764 (dashed) in $s^{-1}$ at different solar zenith angles (SZA), calculated at a Sun-Mars distance of 1.52 AU. Right)

765 Ratio of the $\mathrm{H}_{2} \mathrm{O} / \mathrm{HDO}$ photolysis rates as a function of SZA. 

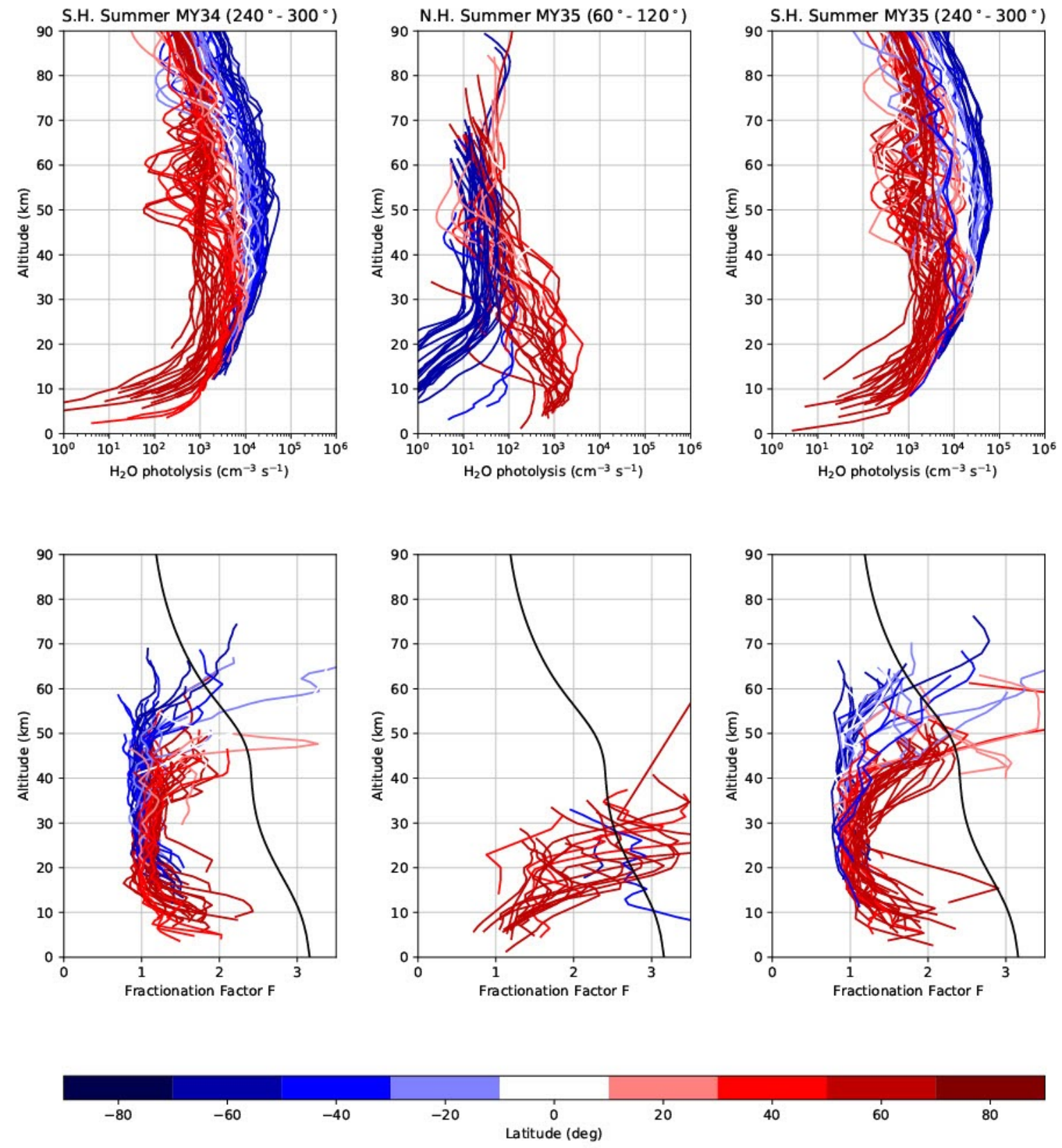

767 Figure S11: Comparison of the estimated impact of fractionation during photolysis for the perihelion and

768 aphelion seasons during MY34 and MY35. The top panels show the estimated $\mathrm{H}_{2} \mathrm{O}$ dissociation rates, with the

769 colour of the lines representing the latitude of the observations. The bottom panels show the fractionation factor

770 between the D/H ratio representative of water vapour in the lower atmosphere and that of the photolysis

771 products for the cases of photolysis-induced fractionation $F_{\text {photo }}=J_{H 2 O} J_{H D O}$ (black line) and

772 condensation-induced fractionation $F^{\prime}{ }_{\text {cond }}=(D / H)_{\text {bulk }}(D / H)_{\text {parent }}($ colour-coded lines $)$. 

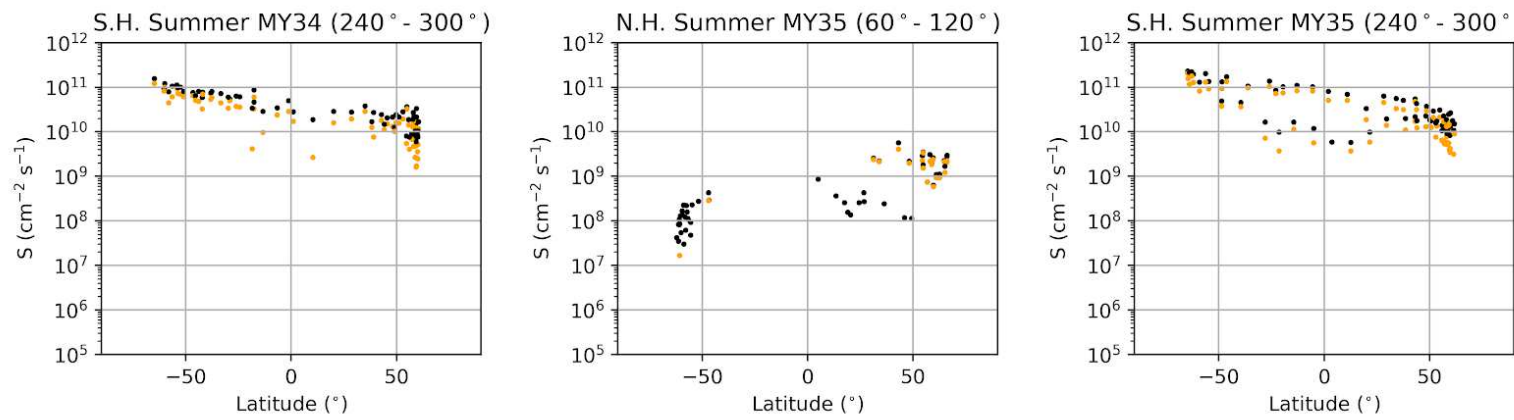

774
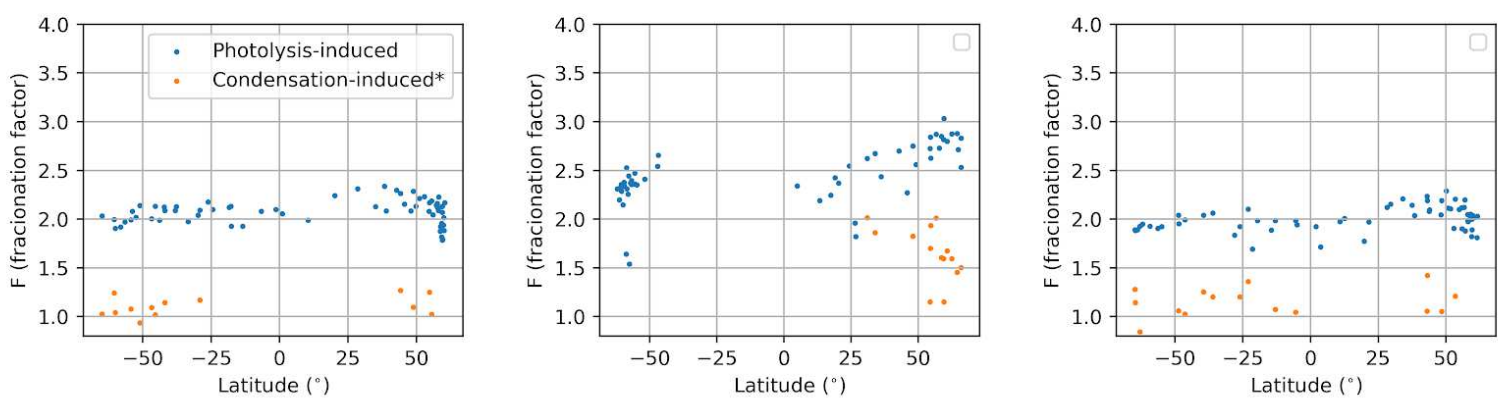

775 Figure S12: Column-integrated water vapour photolysis rates and D/H fractionation factors for the

776 perihelion and aphelion seasons during MY34 and MY35. The top panels show the column-integrated

777 photolysis rates (black dots) as a function of latitude. The yellow dots represent the column-integrated

778 photolysis rates when using the part of the column in which the measurements are sensitive to HDO. The bottom

779 panels show the fractionation factors between the D/H ratio representative of the lower atmosphere and that of

780 the photolysis products $\left(F=(D / H)_{\text {bulk }} /(D / H)_{\text {products }}\right)$ for the cases of photolysis-induced fractionation (blue dots)

781 and condensation-induced fractionation (orange dots). The condensation-induced fractionation factor is only

782 plotted if the column-integrated photolysis rate using the part of the column in which the measurements are

783 sensitive to HDO (yellow dots in top panels) is at least 75\% of that calculated when using the whole column

784 (black dots in top panels). 

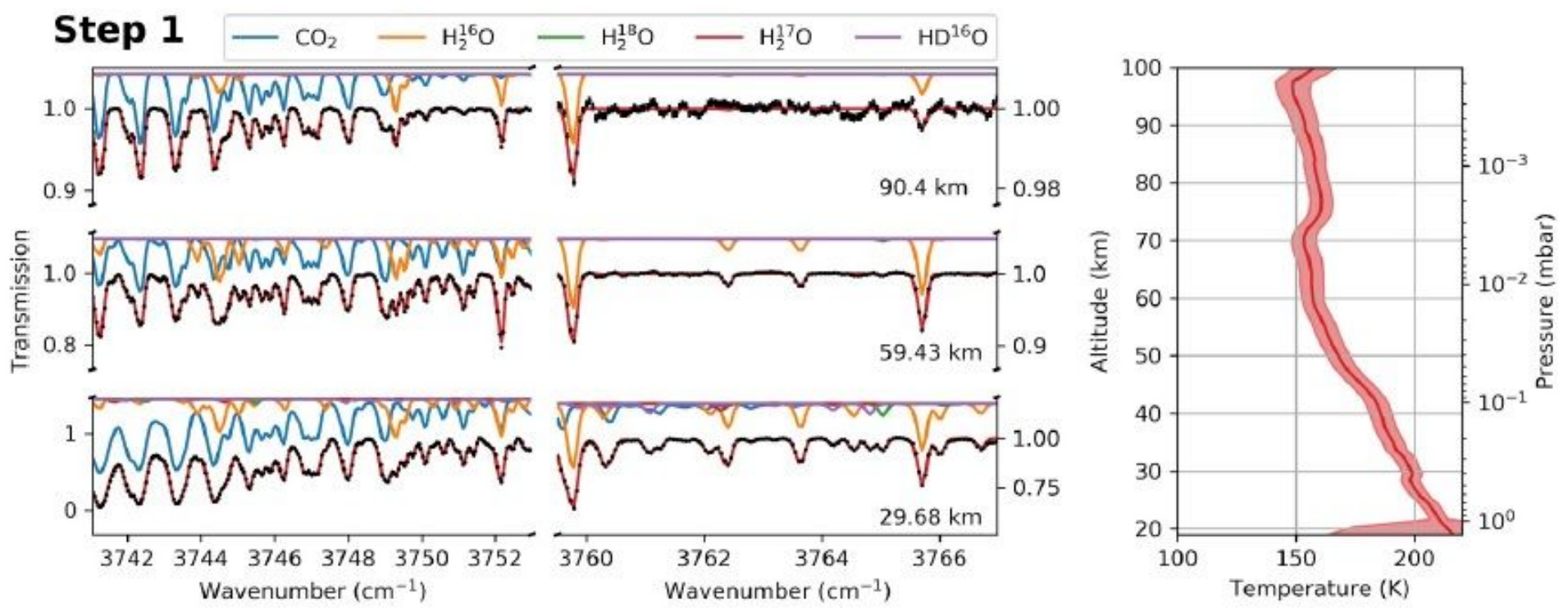

\section{Step 2}
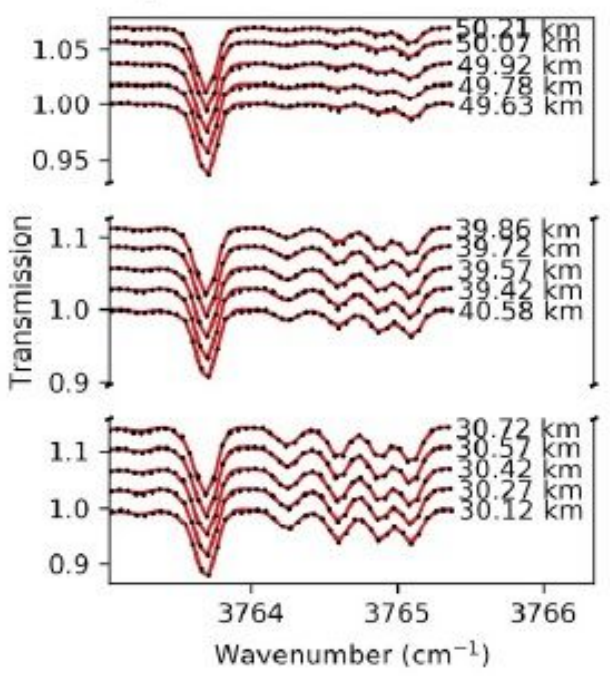

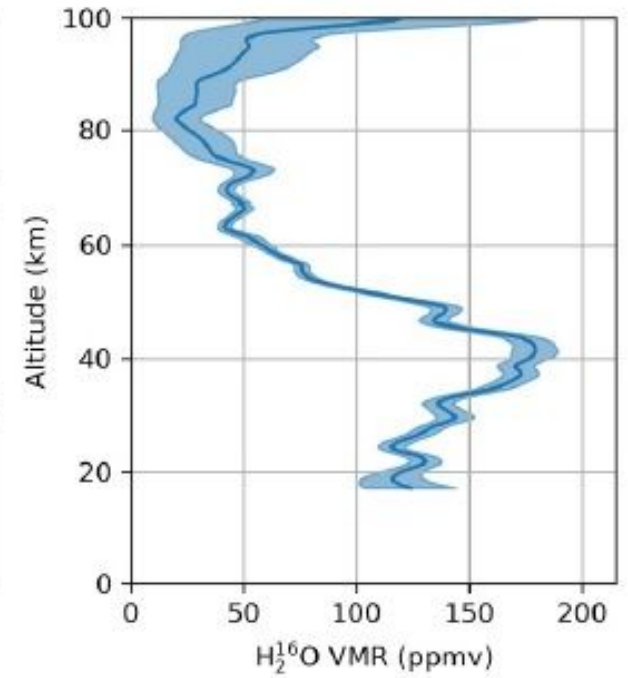

Figure 1

Example of ACS MIR spectra and summary of the retrieval scheme. A CS MIR spectra shown in this figure was o btained in orbit 4409 (Latitude $=42^{\circ} \mathrm{S}, \mathrm{Ls}=291^{\circ}$, Local time $\left.=19 \mathrm{~h}\right)$. In step 1 of the retrieval scheme, pressure and temperature based on the absorption of $\mathrm{CO} 2$, and $\mathrm{H} 2 \mathrm{O}$ volume mixing ratio profiles are retrieved from one detector row in diffraction orders 223 and 224. In step 2, spectra from five different detector rows are independently used to retrieve the volume mixing ratios of $\mathrm{H} 2 \mathrm{O}, \mathrm{H} 2 \mathrm{O}$ and HD1 60 from the spectral window in diffraction order 224, which allow the derivation of the D/H and $180 / 160$ isotope ratios. 

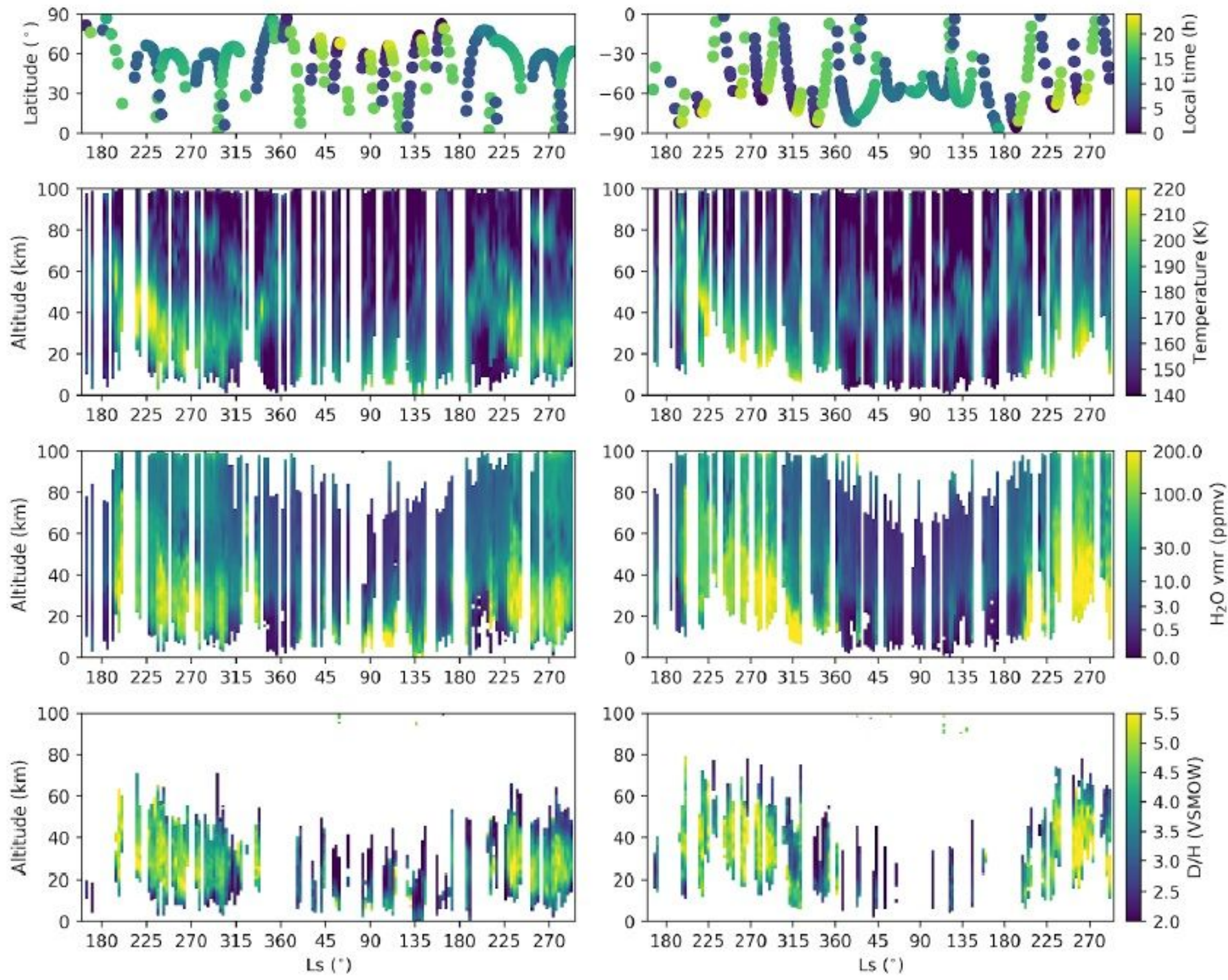

Figure 2

Climatology of the retrieved atmospheric parameters. The panels show the values of the retrieved parameters as a function of altitude and solar longitude for the northern (left) and southern (right) hemispheres. A) Distribution of ACS MIR solar occultation observations, with the local time represented by the colour bar. B) Atmospheric temperature. C) Water vapour volume mixing ratio. E) D/H ratio in water vapour with uncertainties lower than 1 VSMOW. 

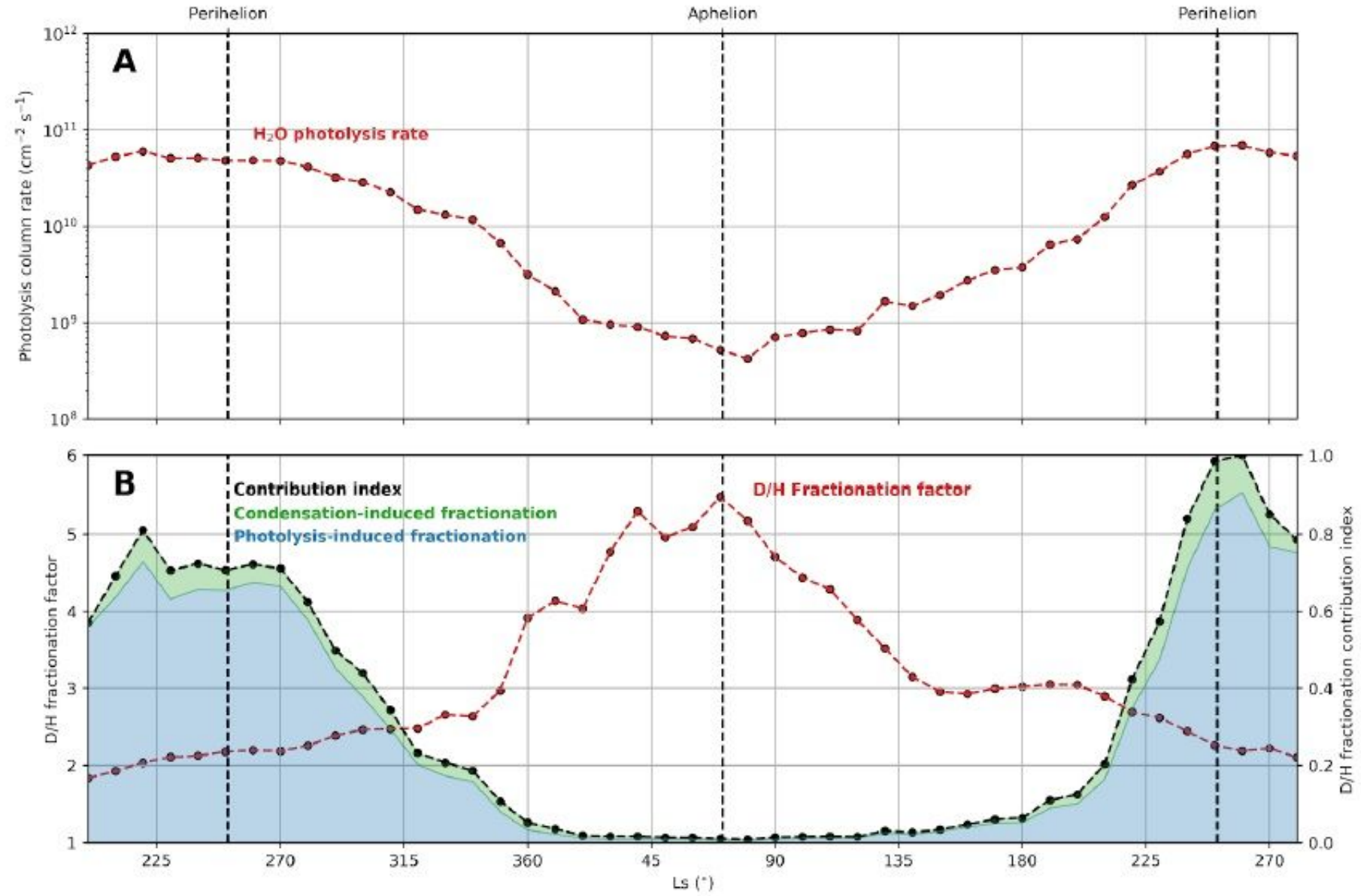

\section{Figure 3}

Seasonal evolution of the isotopic fractionation of $\mathrm{D} / \mathrm{H}$ during the photodissociation of water vapour. A) The column-integrated photolysis rate of water vapour exhibits large seasonal variations, revealing the perihelion season to be dominant in the production of $\mathrm{OH}$ and $\mathrm{H}$. B) The estimated fractionation factor between the value representative of the lower atmosphere (D/H $=5 \mathrm{VSMOW})$ and its photodissociation products $((\mathrm{D} / \mathrm{H}) \mathrm{b}$ ulk/ $(\mathrm{D} / \mathrm{H}) \mathrm{p}$ roducts ) (red curve) is anti-correlated with the photolysis of water vapour, peaking near aphelion. Also plotted is the contribution index (normalised photolysis rate of $\mathrm{H} 2 \mathrm{O}$ - black line) of each point to the annual average of the $\mathrm{D} / \mathrm{H}$ fractionation factor, showing the prevalence of the perihelion season on the global scale. The contribution of condensation-induced ( $\mathrm{F}^{\prime} \mathrm{C}$ ond) and photolysis-induced fractionation (F'p hoto) (shaded polygons) to the total $\mathrm{D} / \mathrm{H}$ fractionation factor ( $B$, shaded polygons) demonstrate the prevalence of the latter in shaping the isotopic composition of the escaping hydrogen. 